\title{
Sources of COVID-19 Information Seeking and their Associations with Self-Perceived Mental Health among Canadians
}

Yanli Li, Wilfrid Laurier University, Canada

\begin{abstract}
Using two datasets from the Canadian Perspectives Survey Series (CPSS), this study provides a longitudinal analysis of information sources Canadians consulted regarding COVID-19 and their associations with poor self-perceived mental health (SPMH) during March and July 2020. Nearly $20 \%$ of Canadians who were surveyed reported poor SPMH. The logistic regression results revealed that at Time 2 (July 2020), after controlling for demographic, socio-economic, and psychobehavioural factors, using social media was significantly associated with higher odds of poor SPMH than using six other information sources including news outlets, federal health agencies, provincial health agencies, provincial daily announcements, places of employment, and other sources (for example, schools, colleges, universities). Checking the accuracy of online information more frequently was also associated with lower odds of poor SPMH.
\end{abstract}

Keywords: COVID-19; information seeking; self-perceived mental health; social media

Publication Type: research article

\section{Introduction}

W hen the World Health Organization (WHO) declared the COVID-19 pandemic on March 11,2020 , the world was profoundly affected in many degrees. Studying mental health became important because evidence has shown that mental health can be negatively affected by pandemics such as H1N1 (Lau et al., 2010) and COVID-19 (Wang et al., 2020; Chi et al., 2020). The United Nations even warned of a global mental health crisis due to increasing death counts, isolation, fear, poverty, and anxiety caused by the pandemic (Kelland, 2020). Effects of the pandemic on mental health can be studied in a multidisciplinary fashion by focusing on psychological, social, or population factors.

One of the immediate research priorities is to better understand the effect of repeated media consumption in traditional and social media on mental health (Holmes et al., 2020). There are concerns that misinformation regarding the outcomes, prevention, and cure of the coronavirus disease has bombarded social media and worsened mental health outcomes (Gao et al., 2020; Tasnim et al., 2020). In addition to social media, Canadians can access pandemic-related information through other sources, such as news outlets, public health agencies, family/friends/colleagues, health professionals, schools/colleges/universities, places of employment, among others. It is important to thoroughly examine the main information sources consulted by Canadians. Although some research has indicated that Canadians reported lower mental health in the pandemic (Findlay \& Arim, 2020), there are not adequate studies on the

The International Journal of Information, Diversity, \& Inclusion, 5(3), 2021

ISSN 2574-3430, https://jps.library.utoronto.ca/index.php/ijidi

DOI: $10.33137 /$ ijidi.v5i3.36193 
influencing factors of their mental health during COVID-19. This research will focus on the association between COVID-19 information seeking and Canadians' self-perceived mental health (SPMH). The findings from this research will help understand Canadians' information seeking behaviours and predictors of mental health during the pandemic.

\section{Research Context and Objectives}

This study uses data from the Canadian Perspectives Survey Series (CPSS) to explore Canadians' mental health across two points in time: March 29, 2020 to April 3, 2020 (referred to as Time 1) and July 20, 2020 to July 26, 2020 (referred to as Time 2). To contextualize this research, it is useful to provide an overview of how the pandemic has evolved in Canada during these times. On January 27, 2020, Canada confirmed its first case of COVID-19 linked to a recent travel to Wuhan, China, where a novel coronavirus was circulating. Ever since the first community transmission case was confirmed on March 5, 2020, COVID-19 spread across Canada rapidly (CTV News, 2021). As of April 3, 2020, the total number of COVID-19 confirmed cases was 12,537 and increased dramatically to 113,911 as of July 26, 2020 (Government of Canada, 2021). Both Time 1 and Time 2 fall within Wave 1 of the pandemic in Canada; however, they are at two different stages. As shown in Figure 1, the 7-day average of new COVID-19 case numbers nationwide was 1,121 as reported on April 3, 2020. The curve on the graph demonstrated an upward trend until it reached the peak of 1,797 cases on May 3, 2020. The federal and provincial governments took measures to control the spread of coronavirus, including social distancing enforcement, nonessential workplaces and school closures, scaling up testing, increasing the contact tracing capacity, a quarantine order for returning travellers, and more (Vogel \& Eggertson, 2020). Thanks to these measures, the curve flattened as cases went down. On July 26, 2020, the 7-day average of new COVID-19 case numbers dropped significantly to 510, suggesting that Canada was past the worst of the first wave of COVID-19.

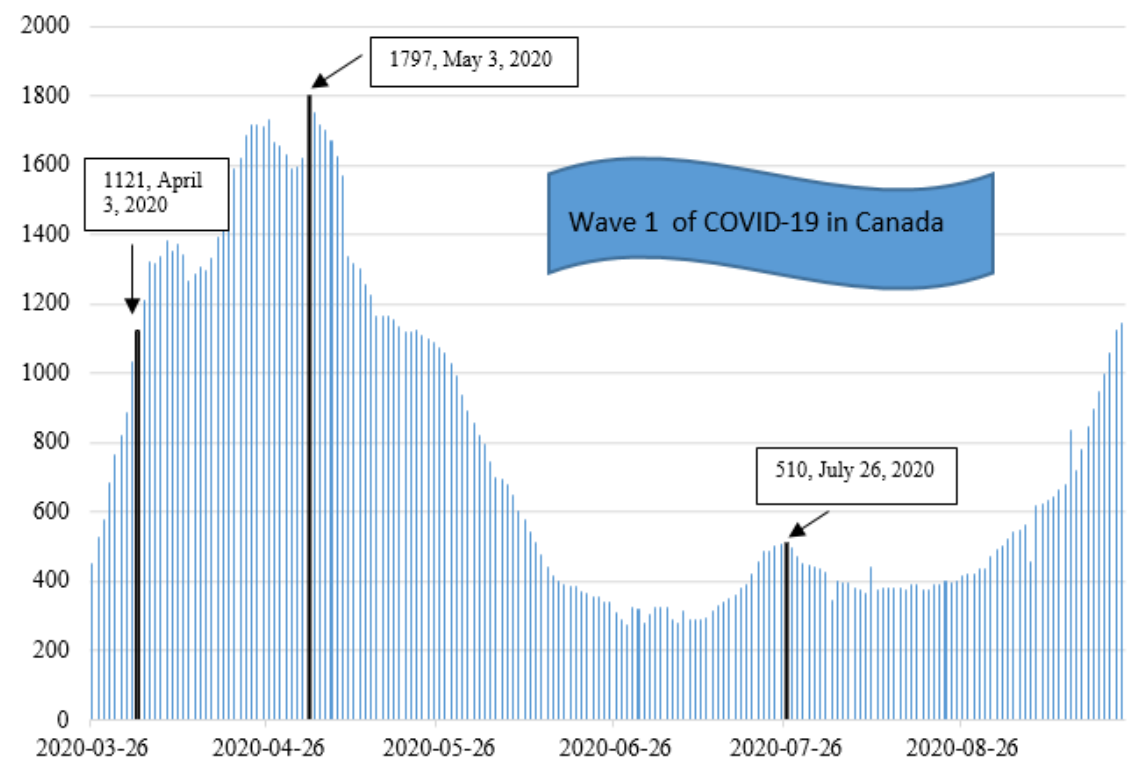

Figure 1. The 7-day average of new COVID-19 case numbers by reporting date. Data source: Government of Canada (2021).

The International Journal of Information, Diversity, \& Inclusion, 5(3), 2021

ISSN 2574-3430, jps.library.utoronto.ca/index.php/ijidi/index

DOI: $10.33137 /$ ijidi.v5i3.36193 


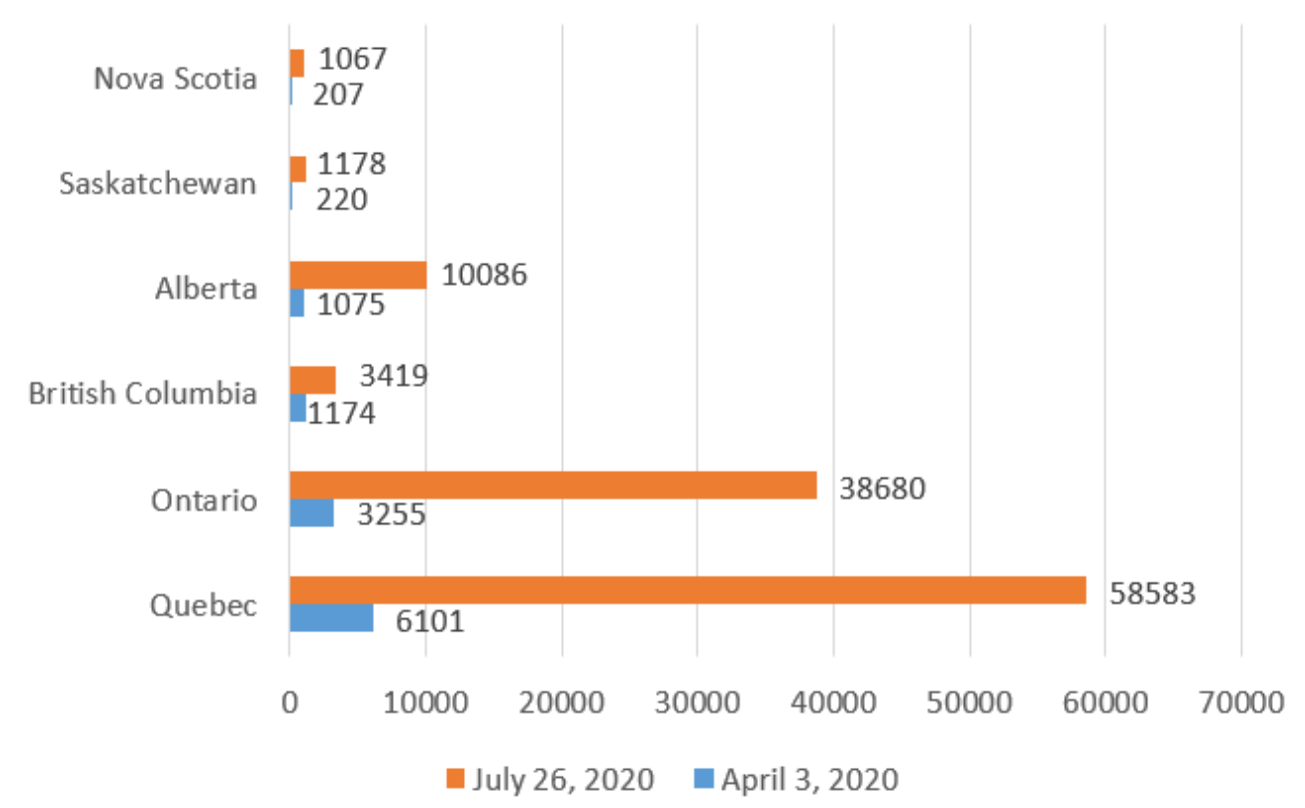

Figure 2. Total number of confirmed cases in selected provinces. Source: Author's tabulations based on data from Government of Canada (2021).

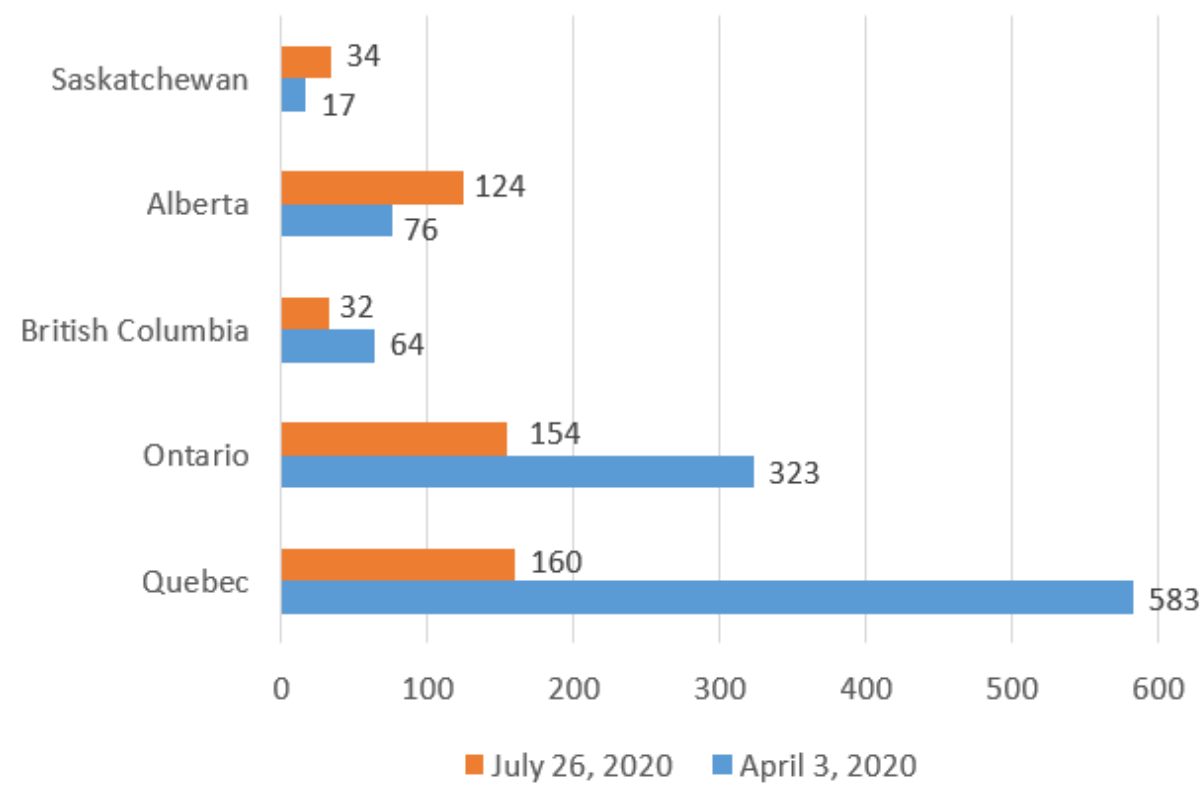

Figure 3. The 7-day average of new case numbers in selected provinces. Source: Author's tabulations based on data from Government of Canada (2021).

The International Journal of Information, Diversity, \& Inclusion, 5(3), 2021

ISSN 2574-3430, jps.library.utoronto.ca/index.php/ijidi/index

DOI: $10.33137 /$ ijidi.v5i3.36193 
Provinces in Canada were hit by COVID-19 to varying degrees over time. By April 3, 2020 at Time 1 , Quebec, Ontario, and British Columbia were the top three provinces in terms of the total number of COVID-19 confirmed cases, whereas Alberta took over British Columbia at the end of Time 2. All provinces except Alberta and Saskatchewan saw a big drop in the 7-day average of new case numbers from Time 1 to Time 2. Figures 2 and 3 show these changes in a few selected provinces.

The effects of the pandemic differed by gender and age group. Figure 4 presents the age distribution of the average number of COVID-19 cases with illness onset over Time 1 and Time 2 . Out of the 1,149 new cases at Time 1, seniors aged 80 and over accounted for the largest percentage (17.5\%), followed by people aged 40-49 (17.1\%) and 50-59 (16\%). At Time 2, young people accounted for a rising percentage of new cases in Canada. Out of the 433 new cases, people aged 20-29 made up more than a quarter. People under 20 made up $18.8 \%$ of the new cases, compared to $5.8 \%$ at Time 1 . Those aged $30-39$ constituted nearly $17 \%$ of the new cases at Time 2, more than 4\% higher compared to Time 1.

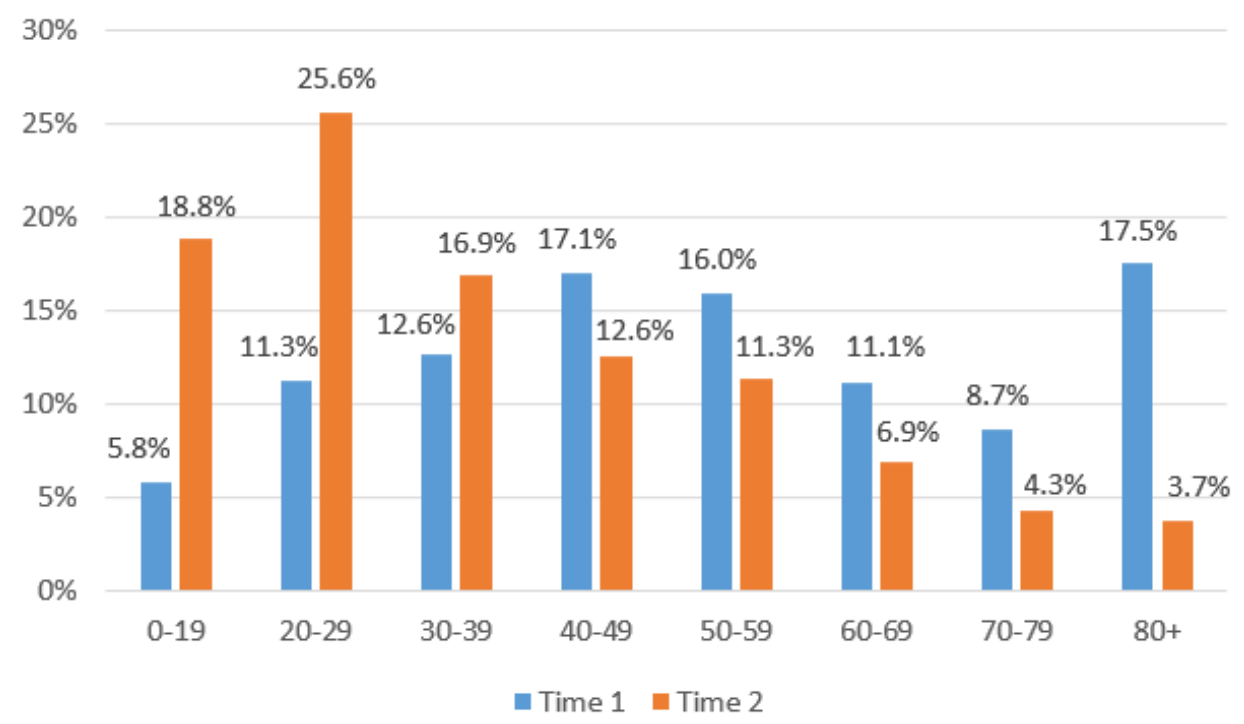

Figure 4. Average of COVID-19 case number, by age group. Sources: Government of Canada (2021) and author's own calculations.

As of June 18, 2021, there were 1,401,236 COVID-19 cases reported in Canada, including 696,268 (49.7\%) male cases and 704,913 (50.3\%) female cases (Government of Canada, 2021). No data are available on the number of COVID-19 cases by gender specifically for Time 1 and Time 2, but some studies report that the pandemic has affected males and females differently. ${ }^{1}$ Despite a recovery in labour market from March 2020 to July 2020, women's employment was consistently more affected than men (Grekou \& Lu, 2021). Work-life balance and childcare challenges affected women more than men, particularly with school closures and reduced availability of social services such as childcare and eldercare (Charnock et al., 2021).

The pandemic has taken an emotional toll on Canadians. Based on Statistics Canada's web panel survey "Canadian Perspectives Survey Series 1: Impacts of COVID-19" from March 29 and April 3,

The International Journal of Information, Diversity, \& Inclusion, 5(3), 2021

ISSN 2574-3430, jps.library.utoronto.ca/index.php/ijidi/index

DOI: $10.33137 /$ ijidi.v5i3.36193 
2020, 53\% of Canadians reported having excellent or very good mental health. This result was 15\% lower than findings from the 2018 Canadian Community Health Survey (CCHS). Age and gender made a difference on mental well-being. Women (49\%) were less likely than men $(60 \%)$ to report excellent or very good mental health during the pandemic, compared to $66 \%$ and $71 \%$ respectively for women and men in the 2018 CCHS. Youth were also less likely to report excellent or very good mental health during the pandemic. Specifically, $42 \%$ of those aged 15 to 24 reported excellent or very good mental health during COVID-19 compared to 62\% in 2018 CCHS (Findlay \& Arim, 2020). Statistics Canada's crowdsource survey “Impacts of COVID-19 on Canadians-Your mental health" from April 24 to May 11, 2020 showed that $57 \%$ of females reported worse mental health since physical distancing began, as did $47 \%$ of males. Symptoms consistent with "moderate" or "severe" generalized anxiety disorder (GAD), a condition characterized by frequent, persistent worry and excessive anxiety about several events, were reported by $29.3 \%$ of females vs. $20.5 \%$ of males, and $30.5 \%$ of females vs. $24 \%$ of males reported that their lives were "quite a bit" or "extremely" stressful (Moyser, 2020).

In this context, this research will examine the prevalence of poor SPMH among Canadians at two time points. A number of studies worldwide reveal that social media is negatively associated with mental health during the pandemic. This research will provide Canadian evidence about the influence of social media on mental health as compared to other information sources. Information about COVID-19 is readily available online. There are concerns about the negative impact of misinformation on mental health. This research will also assess if frequently checking accuracy of online information would make a difference in SPMH amongst Canadians. A variety of demographic, social-economic, and psycho-behavioural factors associated with mental health will be examined as covariates as well.

\section{Literature Review}

\section{Health Information-Seeking and Outcomes}

Information seeking means the active and goal-oriented efforts to obtain specific information in response to an event (Niederdeppe et al., 2007). Health information-seeking behaviour (HISB) refers to "a purposive process of obtaining, clarifying, and confirming information related to physical and mental health conditions, diseases, and lifestyles" (Lu et al., 2020, p. 491). Several health information-seeking models have been proposed. The Comprehensive Model of Information Seeking (CMIS) explores people's information-seeking actions by looking at the role played by demographics (race, education, sex), experience, salience, beliefs, and the information fields in which people exist (Johnson et al., 2001). Anker et al.'s (2011) framework suggests that the practice of health information-seeking is more than merely engagement in a search for information, but involves characteristics of the information seeker, selection and the use of information sources, and the outcomes associated with the search process.

A large body of literature addresses health information-seeking. Researchers have found that the characteristics of health information seekers is associated with their information seeking behaviours. For instance, females, the 30-39 year age group, those with university or higher level of education, and employed individuals were more likely to search for health-related information on the internet (AlGhamdi \& Moussa, 2012). Previous studies have investigated immigrants' general health information-seeking behaviour and focused on specific ethnic groups such as Korean, Iranian, South Asian, Chinese, Mexican, and Hispanic (Mason et al., 2021). Some American studies compare immigrants and native-born population regarding access to health

The International Journal of Information, Diversity, \& Inclusion, 5(3), 2021

ISSN 2574-3430, jps.library.utoronto.ca/index.php/ijidi/index

DOI: $10.33137 /$ ijidi.v5i3.36193 
information (Yoon et al., 2017; Oh et al., 2014), whereas such comparative studies on Canadians are very limited.

Previous studies have not adequately explored the outcomes associated with health informationseeking. A systematic review of literature from 1978 to 2010 indicated that $16.3 \%$ of 129 articles examined the specific information channels referenced by information seekers. About half of these articles employed checklists of available information sources (like internet, primary care physician, TV) to determine the unique sources and total number of sources consulted by participants. However, the majority of these studies did not explore relevant outcomes as a result of engaging in information seeking (Anker et al., 2011). A limited number of studies explore the health outcomes of health information-seeking by medium. For instance, probability-based telephone surveys of Hong Kong residents during 2009-2012 found that poor self-rated health was associated with infrequent health information-seeking from newspapers/magazines and internet (Wang et al., 2013). Among American adults, newspaper health information-seeking was associated with fruit and vegetable consumption, while television health information-seeking was associated with sweetened soft drink consumption. In comparison to the Internet, newspaper and television were associated with healthier lifestyle behaviours to help decrease obesity (Beaudoin \& Hong, 2011). Nevertheless, mental health as a potential outcome resulting from information seeking has been understudied.

There has been much discussion about the link between social media and mental health. The findings before COVID-19 are mixed. Feder et al. (2020) revealed that frequent social media use was associated with greater symptoms of psychopathology. In contrast, Berryman et al. (2018) did not support that social media use was a predictor of mental health problems. Likewise, time spent using social media was not found to be related to individual changes in depression or anxiety across development (Coyne et al., 2020). Some studies have indicated that social media use may be beneficial for some individuals such as adolescents (O'Reilly et al., 2019; O'Reilly, 2020) and people with mental illness (Naslund et al., 2019). Comparatively, in the wake of COVID19 , studies predominantly suggest that social media is not a reliable information source; some even identify it as a stressor. Misinformation and rumors rampant on social media can promote the practice of unhealthy behaviours that may increase spread of the virus. This would ultimately cause poor physical and mental health outcomes (Tasnim et al., 2020). Twitter and Facebook play a role in spreading fear and panic, and making negative impacts on public psychological wellbeing (Ahmad \& Murad, 2020; Lwin et al., 2020). Furthermore, frequent social media exposure was associated with greater mental health problems such as anxiety and depression (Gao et al., 2020; Li et al., 2021; Ni et al., 2020).

\section{Mental Health Impacts of COVID-19}

Mental health is an integral component of health. WHO (2018) defines mental health as "a state of well-being in which an individual realizes his or her own abilities, can cope with the normal stresses of life, can work productively and is able to make a contribution to his or her community." A wide range of indicators can be used to measure mental health. In Canada, Mental Health Commission of Canada (MHCC) (2021) presents 55 indicators reflecting mental health for children and youth, adults, and seniors. Some studies examine general mental health, whereas others assess diagnosis-specific domains of mental health (e.g., anxiety disorders, post-traumatic stress, depressive disorders) (Mansfield et al., 2020). Research has found a disagreement between self-reported level of mental health and clinical diagnoses (Eaton et al., 2000).

The International Journal of Information, Diversity, \& Inclusion, 5(3), 2021

ISSN 2574-3430, jps.library.utoronto.ca/index.php/ijidi/index

DOI: $10.33137 /$ ijidi.v5i3.36193 
However, it is very common that researchers employ self-report instruments to study mental health, although they use different terms such as self-perceived, self-reported, and self-rated.

Regarding the mental health impacts of COVID-19, studies at the beginning of the pandemic originated from various countries such as China, Canada, Iran, Japan, Singapore, and Brazil. They focused on the general population, healthcare workers, and vulnerable populations including seniors, the homeless, international migrant workers, people with existing mental issues, pregnant women, and students studying overseas (Rajkumar, 2020). Most of these articles are commentaries or editorials. Two editorial papers from Canada addressed health anxiety as an impact of COVID-19 on mental health. Exposure to inaccurate or exaggerated information from the media may cause excessive health anxiety, possibly demonstrated through repeated medical consultations, avoiding health care in case of illness, or stocking up on particular items (Asmundson \& Taylor, 2020a, 2020b).

As the COVID-19 pandemic evolves, growing evidence based on survey data supports its pervasive impact on individual's mental health worldwide. The prevalence of poor mental health in the existing studies varies due to the differences in study population, study time, scales, measures, and methodologies. Around $10 \%$ of Chinese college students had persistent and/or developed new mental health problems ( $\mathrm{Li}$ et al., 2021). Over one-quarter of the respondents $(26.8 \%)$ in Hubei Province of China displayed clinically significant psychological distress symptoms (Zhou \& Guo, 2021). In Lombardy, Italy, 39.8\% of the health workers developed post-traumatic stress disorder (Bassi et al., 2021). In Canada, according to the "National Monitoring Survey - Assessing the Impacts of COVID-19 on Mental Health" in late January 2021, 77\% of adults reported feeling negative emotions (e.g., worried or anxious, stressed, lonely or isolated, sad) (Canadian Mental Health Association, 2021).

\section{Models of Determinants of Mental Health}

Numerous studies have addressed the determinants of mental health based on various analysis frameworks or models (Li et al., 2021; Robert \& Gilkinson, 2012; Salami et al. 2017; Zhou et al., 2020). Robert and Gilkinson's (2012) analysis framework recognizes that mental health is influenced by socio-demographic, socio-economic, social networking, health utilization, and psycho-social variables. In their research, they explored the mental health outcomes of recent immigrants in Canada, including prevalence of emotional problems, stress levels, and main sources of stress. The above-mentioned variables associated with the incidence of emotional problems and stress were examined through logistic regression. With regards to the specific factors associated with mental health during COVID-19, a number of publications (Chi et al., 2020; Qiu et al., 2020; Smith et al., 2020; Thomas et al., 2020; Wang et al., 2020; Zhou et al., 2020) perform regression models (e.g., multivariable logistic regression, multiple linear regression, and RIDGE regression). The majority of these studies do not include information seeking as a factor of mental health outcomes nor do they focus on Canadians. However, they provide valuable insights into this present study pertaining to model development and variable selection.

Three Chinese studies conducted during the early months of the pandemic are noteworthy. Gao et al. (2020) found that frequent social media exposure was positively associated with high odds of anxiety while controlling for gender, age, education, marital status, self-rated health, occupation, cities, and urban/rural area. In a nationwide large-scale study, Qiu et al. (2020) found that females, young adults (18-30) and the elderly $(60+)$, migrant workers, people with

The International Journal of Information, Diversity, \& Inclusion, 5(3), 2021

ISSN 2574-3430, jps.library.utoronto.ca/index.php/ijidi/index

DOI: $10.33137 /$ ijidi.v5i3.36193 
higher education, and people living closer to the epicenter were associated with psychological distress. A longitudinal study by Wang et al. (2020) revealed that having confidence in doctors, satisfaction with health information, and adopting precautionary measures were significant factors to protect against stress, anxiety, and depression.

In addition, several studies from other countries are worth inclusion. A study by Smith et al. (2020) identified females, younger age groups, those with a lower annual income, and current smokers as associated with higher levels of poor mental health in the United Kingdom. For adults in the United Arab Emirates, younger age, being female, having a history of mental health problems, self or loved ones testing positive for COVID-19, and high levels of COVID-related anxiety were significantly associated with both depression and anxiety (Thomas et al., 2020). A longitudinal American study by Zhou et al. (2020) between April and May 2020 examined the influence of demographic, psychosocial, and behavioural factors on mental health outcomes. Younger adults, people with pre-existing health conditions, and those experiencing greater perceived risk, higher levels of rumination or co-rumination, greater social strain, or less social support all reported worse mental health.

Regarding the association of immigration status with mental health, there have been mixed findings from different countries prior to COVID-19 (Menezes et al., 2011). Previous Canadian studies have confirmed the "healthy immigrant effect". It suggests that immigrants enjoy better mental health than the native-born population at arrival, but this effect tends to decline as their years in Canada increase (Lou \& Beaujot, 2005; Ng, 2011; Ng \& Zhang, 2020). Without considering years since immigration, some studies found that immigrants had a lower rate of mental health problems such as depression (Ali, 2002) and bipolar disorder (Schaffer et al., 2009). In contrast, Salami et al.'s (2017) analysis revealed that the difference in the self-perceived mental health of immigrants versus non-immigrants was not statistically significant. Research probing immigration status and mental health during the COVID-19 pandemic is scarce. Survey data showed that recent immigrants reported fair or poor mental health more often than other Canadians (Evra \& Mongrain, 2020). Immigrants reported elevated levels of concern than Canadian-born individuals about their own health, civil disorder, social ties, and the ability to cooperate, but how the concerns might influence their mental health was unclear (LaRochelleCôté \& Uppal, 2020). This study will include immigration status as a variable in the regression model. However, years since immigration cannot be examined as it is not available in the CPSS data on which this research is based.

\section{Data and Methodology}

\section{Data Sources}

This research performed a secondary data analysis based on two CPSS surveys. CPSS, sponsored by Statistics Canada, is a set of five short, online surveys conducted between March and September 2020. The purpose of CPSS is to gather information quickly on the knowledge and behaviours of residents of the 10 Canadian provinces. Governments and organizations may use this information to make informed decisions on delivery of social services or support to Canadians during and after the pandemic. Each CPSS survey is cross-sectional and administered to a subset of Labour Force Survey (LFS) respondents. The CPSS survey population includes full-time members of the Canadian Armed Forces, while excluding those living on reserves and other Aboriginal settlements in the provinces, the institutionalized population, and households in

The International Journal of Information, Diversity, \& Inclusion, 5(3), 2021

ISSN 2574-3430, jps.library.utoronto.ca/index.php/ijidi/index

DOI: $10.33137 /$ ijidi.v5i3.36193 
extremely remote areas with very low population density. These participants represent less than 2\% of the Canadian population aged 15 and over as of July 31, 2019 (Statistics Canada, 2020a).

This study is based on two CPSS surveys: "CPSS1- Impacts of COVID-19" and "CPSS4 - Information Sources Consulted during the Pandemic" (Statistics Canada, 2020b, 2020c). CPSS1 collected data from March 29, 2020 to April 3, 2020 (Time 1) and CPSS4 collected data from July 20, 2020 to July 26, 2020 (Time 2). The datasets from these two surveys contain valuable information, including the main source of information that Canadians consulted about COVID-19, selfperceived mental health, and demographic, employment, and behavioural information for individuals. The public use microdata files (PUMF) were downloaded via Odesi (Ontario Data Documentation, Extraction Service and Infrastructure), which is a digital repository of Canadian social science datasets. The respondents were excluded if their data were missing for any of the variables examined in this research. The final dataset thus comprised 3,862 records from CPSS1 and 3,795 records from CPSS4.

\section{Analytical Techniques}

Cross-tabulations were used to estimate the number and percentage of Canadians using each information source about COVID-19, and the percentage of Canadians who reported poor SPMH. Because of evidence showing demographic differences in health information-seeking and mental health outcomes, separate analyses were made by gender, age group, and immigration status. To gain insights into the associations between sources of information and individuals' mental health, the following logistic regression model was fitted to predict the odds of reporting poor SPMH:

Logit $(p)=B_{0}+B_{1} *$ infosource $+B_{j} * X_{j}$

Model (1) includes the explanatory variable information source (infosource) and covariates $X_{j} . B_{0}$ represents the intercept, $B_{1}$ is coefficient for information source and $B_{j}$ is coefficient for each covariate as described in the Measures section. These coefficients represent the expected change in the log odds of reporting poor SPMH for a unit increase in the corresponding explanatory variable, while holding the other explanatory variables constant at certain values. The odds ratios are obtained by exponentiating the coefficients for the explanatory variables. For instance, the odds ratio for variable News Outlets compares using news outlets with using social media (as reference group) in the odds of reporting poor SPMH.

The CPSS surveys were based upon a complex sample design with stratification, multiple stages of selection, and unequal probabilities of selection of respondents (Statistics Canada, 2020d, 2020e). This research applied analytic weights when producing estimates to be representative of the survey population. Moreover, CPSS used a bootstrap method in resampling, yet the bootstrap weights (used in the calculation of variances) were not provided with the PUMF because of confidentiality. As such, variances of the estimated odds ratios from the regression models could not be adjusted, which might result in underestimation of variability and too many significant results. To mitigate this effect, a more conservative significance level $(p<0.01)$ was employed as the threshold for statistical significance. All analyses were conducted using STATA 13.

The International Journal of Information, Diversity, \& Inclusion, 5(3), 2021

ISSN 2574-3430, jps.library.utoronto.ca/index.php/ijidi/index

DOI: $10.33137 /$ ijidi.v5i3.36193 


\section{Measures}

\section{Poor Self-Perceived Mental Health (Poor SPMH)}

CPSS1 and CPSS4 asked respondents the same question: "In general, would you say that your mental health is excellent? Very good? Good? Fair? Poor?" Similar to Lou and Beaujot (2005) and Wang et al. (2013), responses of fair or poor were categorized as poor self-perceived mental health. Hence, it is a binary outcome variable that takes on values of 0 or 1 .

\section{Information source (infosource)}

The respondents were asked: "What is your main source of information to find out about COVID19? e.g., symptoms, how and when to get tested, closures, travel restrictions and recommendations, maintaining good mental and physical health." There were 13 response categories in CPSS1, but CPSS4 combined the category school, universities and colleges with others due to small counts and confidentiality reasons. To make a comparison over time, this research combined the category school, universities and colleges with others for CPSS1. Ultimately, the following 12 categories of information sources were examined: news outlets, federal health agency, provincial health agency, municipal health agency, federal daily announcements, provincial daily announcements, social media, family/friends/colleagues, health professionals, places of employment, other sources, and did not look for any information. The respondents can only select one response category.

\section{Covariates}

This research referred to Robert and Gilkinson (2012)'s analysis framework. Lou and Beaujot (2005), Ali (2002) and other studies included in the literature review demonstrated the associations between mental health and a wide range of variables. Considering the variables available in CPSS1 and CPSS4, this research will control for demographic, socio-economic, and psycho-behavioural indicators that have possible effects on mental health of Canadians in the context of COVID-19.

\section{Demographic Indicators}

The population was separated into seven age groups: 15 to 24,25 to 34,35 to 44,45 to 54,55 to 64,65 to 74 , and 75 years or older. Regarding immigration status, respondents were grouped into the Canadian-born population and immigrants. Canadian-born refers to people who are Canadian citizens by birth. Those who were born outside of Canada were categorized as immigrants, including landed immigrants and non-landed immigrants. Similar to Robert and Gilkinson (2012) and Gao et al. (2020), marital status was recoded and grouped into two categories: married/common-law and other (i.e., single, divorced, separated, or widowed).

\section{Socio-Economic Indicators}

In their research, Robert and Gilkinson (2012) assigned two categories to employment status: employed and not employed. Taking inspiration from their model, and to reflect the labour market dynamics during COVID-19, this research added more categories to the Robert and Gilkinson model, including employed and at work, employed but absent from work due to COVID19 reasons, employed but absent from work due to non-COVID reasons, and not employed.

The International Journal of Information, Diversity, \& Inclusion, 5(3), 2021

ISSN 2574-3430, jps.library.utoronto.ca/index.php/ijidi/index

DOI: $10.33137 /$ ijidi.v5i3.36193 
Highest education was grouped into five categories: less than high school, high school, college, bachelor's degree, and advanced degree (master's or above). The housing-built environment was found to be associated with mental health during COVID-19 lockdown (Amerio et al., 2020). Hence, this research included two variables to capture the household environment: dwelling type and household size.

\section{Psycho-Behavioural Indicators}

Similar to Gao et al. (2020), self-rated health was included as an indicator of one's overall health status and had five categories: poor, fair, good, very good, and excellent. To capture the precautions taken to reduce the risks of exposure to COVID-19, the respondents in CPSS1 were given the option of answering yes or no to 12 questions, including stocking up on essentials, filling prescriptions, making plans to care for ill family members, practicing social distancing, working from home, washing hands regularly, avoiding touching face, among others. CPSS4 had an additional question compared to CPSS1: "Do you wear a mask?" To achieve consistency across two time points, the responses for this question were added into the other category. Based on the questions above, the variable "precautions" was measured by the total count of the yes responses; a higher count indicated more precautions taken to reduce risks of COVID-19. Similarly, the variable "activities" was created to capture how many types of activities the respondents engaged in to improve their physical or mental health, including meditation, exercising indoors, exercising outdoors, communication with family and friends, and changing food choices. In addition, the variable "concerns" was created to measure the level of concerns that the respondents had regarding the impacts of COVID-19. Participants responded to 12 items using 4-point scales ( $1=$ not at all, $2=$ somewhat, $3=$ very, and $4=$ extremely). The sum of an individual's response score ranged from 12 to 48, with a higher score indicating a higher level of concerns for COVID-19.

Details of the sample characteristics at two time points are shown in Table 1. The sample was divided near-evenly between males and females, and they were primarily Canadian-born individuals. Among the seven age groups, there was less representation from those aged 75 and older. Around $28 \%$ possessed a bachelor's degree or higher. Over $60 \%$ were married or in a common-law relationship. About 50\% were employed and at work, whereas nearly $40 \%$ were unemployed. The percentage of those employed and at work increased from $47 \%$ at Time 1 to $53 \%$ at Time 2, whereas the individuals being absent from work due to COVID-19 reduced from $9 \%$ to nearly $3 \%$ over time. The increase in employment at Time 2 could be related with the government measures dedicated to supporting businesses. For example, the Canadian government provided financial support for small businesses, helped young people find summer jobs, and expanded access to the COVID-19 Emergency Response Act to better support businesses (Canadian Public Health Association, 2021). In addition, over $60 \%$ of the sample lived in single detached houses. Nearly half of the sample had two members in their household. Almost $69 \%$ indicated their self-rated health was very good or excellent at Time 1, as compared to $63 \%$ at Time 2. Comparing Time 2 with Time 1, Canadians took more precautions to reduce the risk of exposure to COVID-19, did more activities to improve physical and mental health, and reported a lower level of concerns for the pandemic.

The International Journal of Information, Diversity, \& Inclusion, 5(3), 2021

ISSN 2574-3430, jps.library.utoronto.ca/index.php/ijidi/index

DOI: $10.33137 /$ ijidi.v5i3.36193 
Table 1. Sample Characteristics

\begin{tabular}{|c|c|c|}
\hline Measures & $\begin{array}{l}\text { Time } 1 \\
\mathrm{~N}(\%) \\
\end{array}$ & $\begin{array}{l}\text { Time } 2 \\
\mathrm{~N}(\%) \\
\end{array}$ \\
\hline Overall & $3862(100)$ & $3795(100)$ \\
\hline \multicolumn{3}{|l|}{ Gender } \\
\hline Male & 1883 (48.77) & $1856(48.91)$ \\
\hline Female & $1979(51.23)$ & 1939 (51.09) \\
\hline \multicolumn{3}{|l|}{ Age group } \\
\hline 15 to 24 & $601(15.56)$ & $546(14.38)$ \\
\hline 25 to 34 & $707(18.32)$ & $659(17.38)$ \\
\hline 35 to 44 & $663(17.17)$ & $643(16.94)$ \\
\hline 45 to 54 & 617 (15.97) & $602(15.87)$ \\
\hline 55 to 64 & $620(16.06)$ & $631(16.61)$ \\
\hline 65 to 74 & $505(13.07)$ & $510(13.45)$ \\
\hline $\begin{array}{l}75+ \\
\text { Immigration status }\end{array}$ & $149(3.85)$ & $204(5.37)$ \\
\hline Canadian-born & $2963(76.71)$ & $2894(76.25)$ \\
\hline Immigrants & $899(23.29)$ & $901(23.75)$ \\
\hline \multicolumn{3}{|l|}{ Education } \\
\hline Less than high school & $515(13.35)$ & $437(11.52)$ \\
\hline High School & $1043(27.00)$ & $1030(27.15)$ \\
\hline College & 1197 (30.99) & $1224(32.25)$ \\
\hline Bachelors & $769(19.91)$ & 742 (19.55) \\
\hline Advanced & $338(8.75)$ & $362(9.54)$ \\
\hline \multicolumn{3}{|l|}{ Marital status } \\
\hline Married/common-law & $2425(62.78)$ & $2333(61.48)$ \\
\hline Other & $1437(37.22)$ & $1462(38.52)$ \\
\hline \multicolumn{3}{|l|}{ Employment status } \\
\hline Employed and at work & $1828(47.34)$ & $2018(53.18)$ \\
\hline Absent not due to COVID-19 & $139(3.59)$ & $226(5.96)$ \\
\hline Absent due to COVID-19 & $354(9.16)$ & $97(2.55)$ \\
\hline Not employed & $1541(39.91)$ & $1454(38.30)$ \\
\hline \multicolumn{3}{|l|}{ Dwelling type } \\
\hline Single detached house & $2454(63.53)$ & 2367 (62.37) \\
\hline Low-rise apartment & $427(11.05)$ & $414(10.90)$ \\
\hline High-rise apartment & $312(8.09)$ & $336(8.86)$ \\
\hline Other & $669(17.33)$ & $678(17.87)$ \\
\hline \multicolumn{3}{|l|}{ Household size } \\
\hline 1 & $546(14.13)$ & $578(15.23)$ \\
\hline 2 & $2003(51.85)$ & $2020(53.24)$ \\
\hline 3 & $720(18.64)$ & $638(16.80)$ \\
\hline 4 & $428(11.09)$ & 394 (10.37) \\
\hline $5+$ & $166(4.29)$ & $165(4.36)$ \\
\hline
\end{tabular}

The International Journal of Information, Diversity, \& Inclusion, 5(3), 2021

ISSN 2574-3430, jps.library.utoronto.ca/index.php/ijidi/index DOI: $10.33137 /$ ijidi.v5i3.36193 


\begin{tabular}{lll} 
Self-rated health & & \\
Poor & $41(1.06)$ & $41(1.08)$ \\
Fair & $206(5.33)$ & $269(7.10)$ \\
Good & $927(24.01)$ & $1107(29.17)$ \\
Very Good & $1580(40.90)$ & $1522(40.11)$ \\
Excellent & $1108(28.70)$ & $856(22.54)$ \\
Precautions & $3862($ mean $=6.70)$ & $3795($ mean=7.01) \\
Activities & $3862($ mean=2.74) & $3795($ mean=2.91) \\
Concerns & $3862($ mean=30.06) & $3795($ mean=26.10) \\
\hline
\end{tabular}

\section{Results}

\section{Main Information Sources Canadians Consulted regarding COVID-19}

Figure 5 presents the proportions of each information source used by Canadians. At Time 1, the four most prominent COVID-19 information sources were news outlets (50.9\%), provincial daily announcements $(11.5 \%)$, social media $(10.3 \%)$, and federal daily announcements $(6.6 \%)$. At Time 2 , the first three remained as the most frequented sources $(50.7 \%, 9.4 \%$, and $9.9 \%$ respectively), while the provincial health agency overtook federal daily announcements for fourth place $(9.2 \%)$. The information sources family/friends/colleagues, health professionals, place of employment, and municipal health agency took up a larger proportion at Time 2 as compared to Time 1.

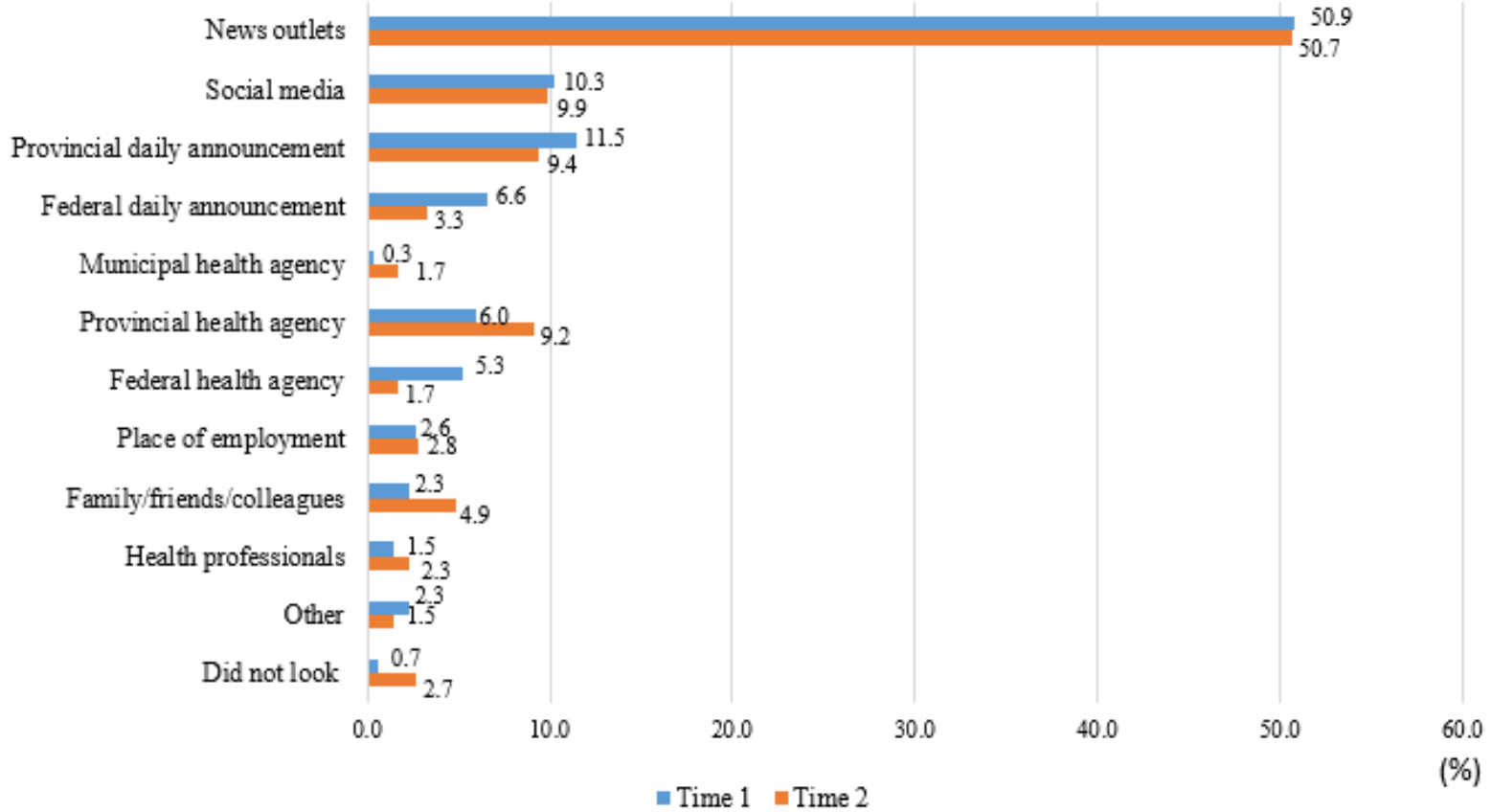

Figure 5. Main information sources consulted by Canadians.

The International Journal of Information, Diversity, \& Inclusion, 5(3), 2021

ISSN 2574-3430, jps.library.utoronto.ca/index.php/ijidi/index

DOI: $10.33137 /$ ijidi.v5i3.36193 
Males were more likely to use news outlets as compared to females (Figure 6). At Time 1, about half of males said that news outlets were their main information source (53.3\% compared to $48.5 \%$ of females). At Time 2, males were again more likely than females to use news outlets, and the difference was even larger than Time 1 (56.1\% compared to $45.5 \%$ of females). Females were more likely than males to use social media. At Time $1,12.5 \%$ of females indicated that social media was their main source of information as compared to $7.9 \%$ of males. Females continued to outweigh males in using social media at Time 2, although the difference was not as large $(10.9 \%$ compared to $8.8 \%$ of males). Females were also more likely than males to consult with provincial health agencies, municipal health agencies, federal daily announcements, family/friends/colleagues, and places of employment at both Time 1 and Time 2. In contrast, males were more likely than females to consult federal health agencies across the two time periods.

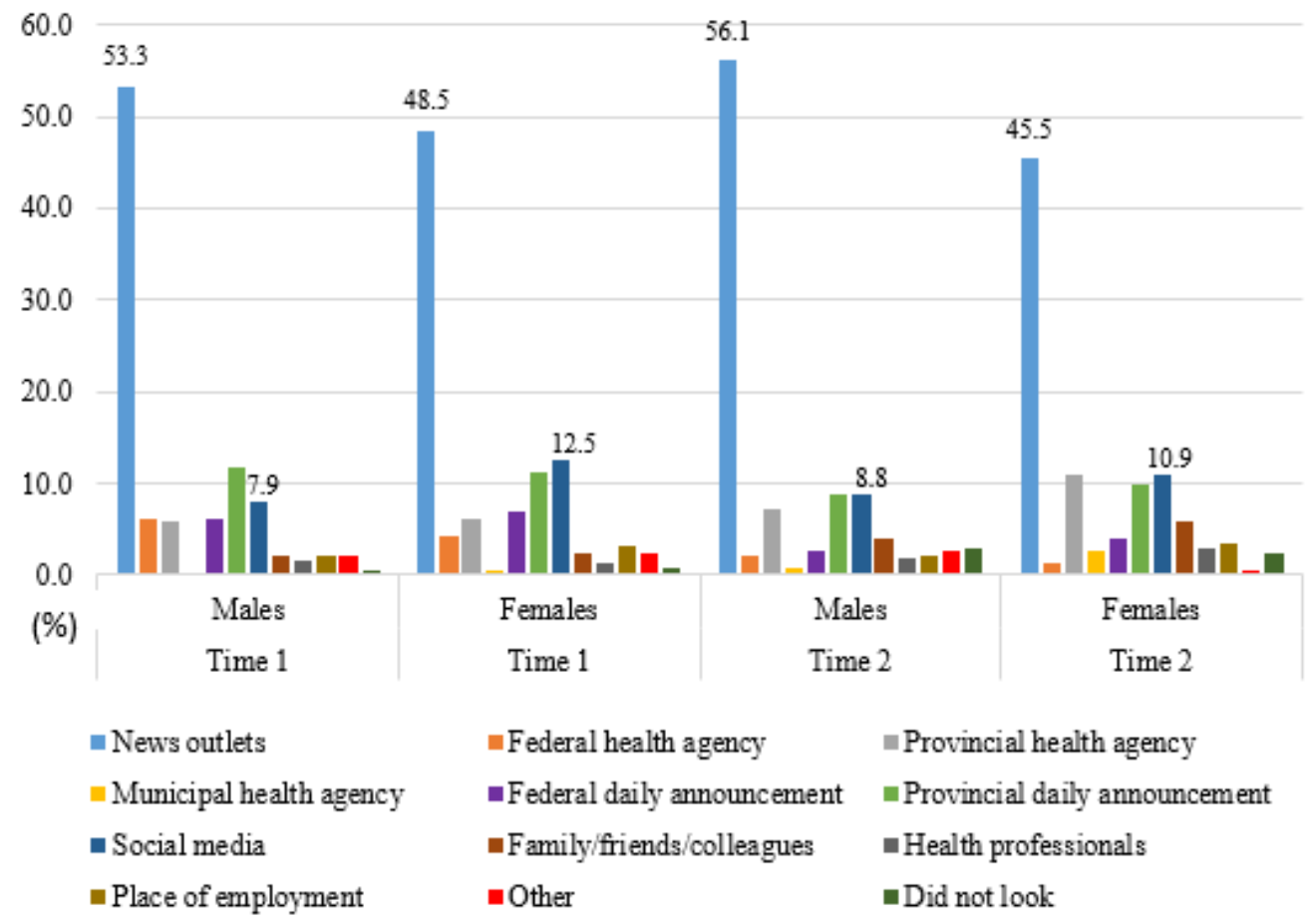

Figure 6. Main information sources, by gender

All age groups were more likely to get COVID-19 information from news outlets than other sources. Particularly, those aged 55 to 64 were more likely to use news outlets than other age groups $(60.4 \%$ at Time 1 and $57.3 \%$ at Time 2$)$. In terms of social media use, those aged 25 to 34 were more likely to use social media although the rate decreased from $8.4 \%$ at Time 1 to $2.6 \%$ at Time 2. In contrast, those aged 75 and older at Time 1 and those aged 55 to 64 at Time 2 were less likely to use social media (Figure 7).

There were notable disparities between the Canadian-born population and immigrants in using information sources. News outlets were the most relied on information sources for both subgroups at both time points. At Time $1,51.9 \%$ of the immigrants and $50.6 \%$ of the Canadian-

The International Journal of Information, Diversity, \& Inclusion, 5(3), 2021

ISSN 2574-3430, jps.library.utoronto.ca/index.php/ijidi/index

DOI: $10.33137 /$ ijidi.v5i3.36193 
born population mainly accessed information from news outlets. The difference was larger at Time 2 (53\% vs. $49.9 \%)$. Regarding social media use, immigrants $(16.8 \%)$ were about twice as likely as the Canadian-born population $(8.3 \%)$ to use social media at Time 1 . At Time 2, immigrants $(11.6 \%)$ still predominated the use of social media compared to the Canadian-born population (9.4\%), yet the difference narrowed. More details are shown in Figure 8.

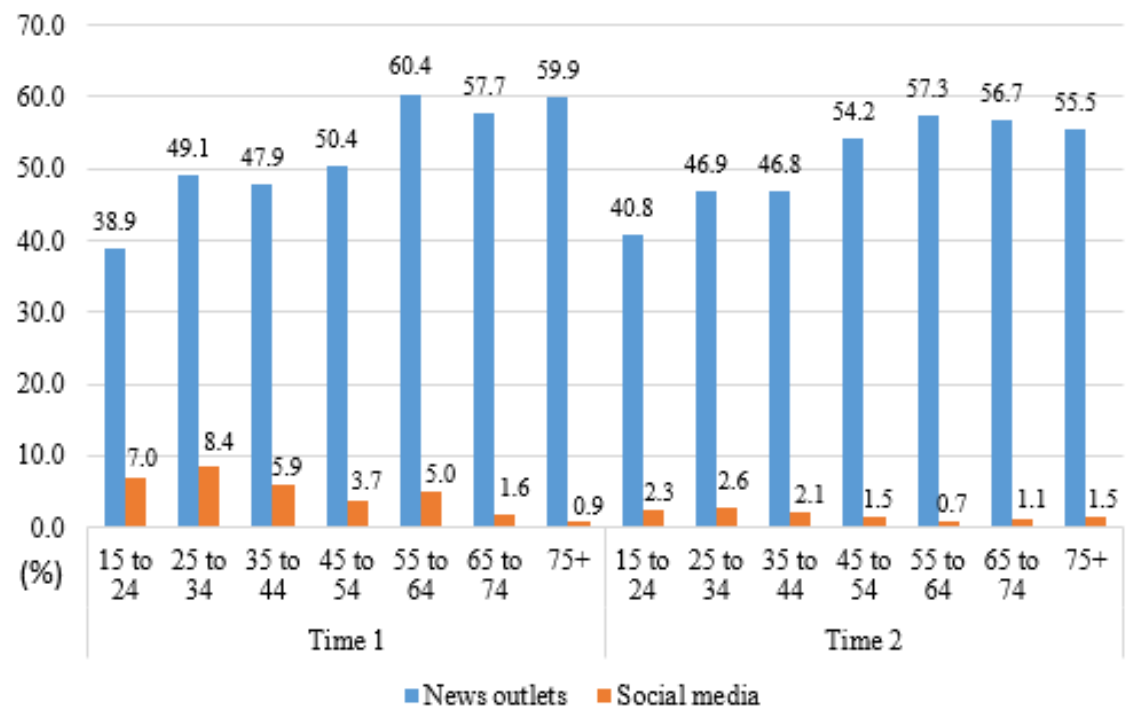

Figure 7. Use of news outlets and social media, by age group

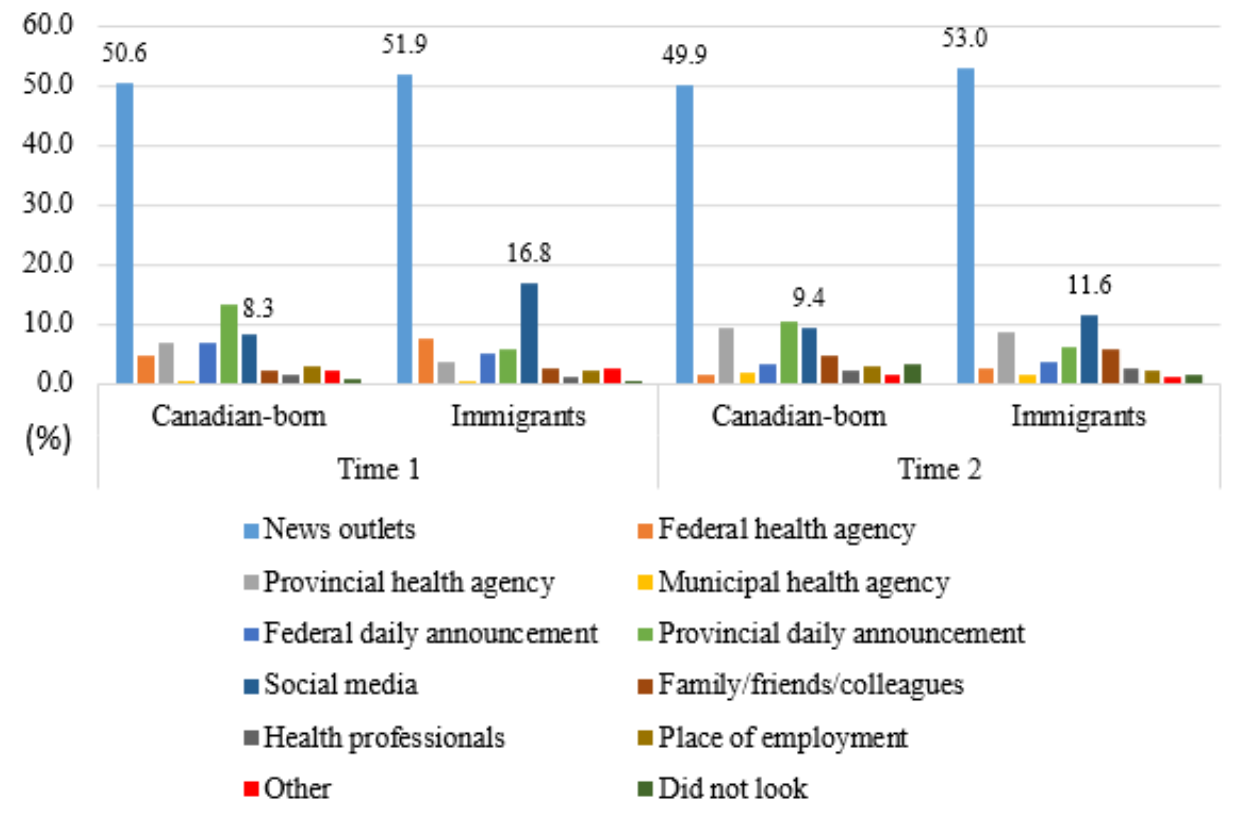

Figure 8. Main information sources, by immigration status

The International Journal of Information, Diversity, \& Inclusion, 5(3), 2021

ISSN 2574-3430, jps.library.utoronto.ca/index.php/ijidi/index

DOI: $10.33137 /$ ijidi.v5i3.36193 


\section{Prevalence of Poor Self-Perceived Mental Health}

This section examined the percentage of Canadians reporting poor SPMH and demographic differences. At Time 1, 18.6\% of Canadians reported poor SPMH as compared to $16.3 \%$ at Time 2, suggesting a slight betterment of Canadians' self-perceived mental health. Figure 9 presents the prevalence of poor SPMH by gender. Females were more likely to report poor mental health than males. At Time 1, 21.4\% of females and $15.6 \%$ of males reported poor mental health. These rates dropped to $19 \%$ and $13.5 \%$ respectively for females and males at Time 2 while the difference was slightly smaller.

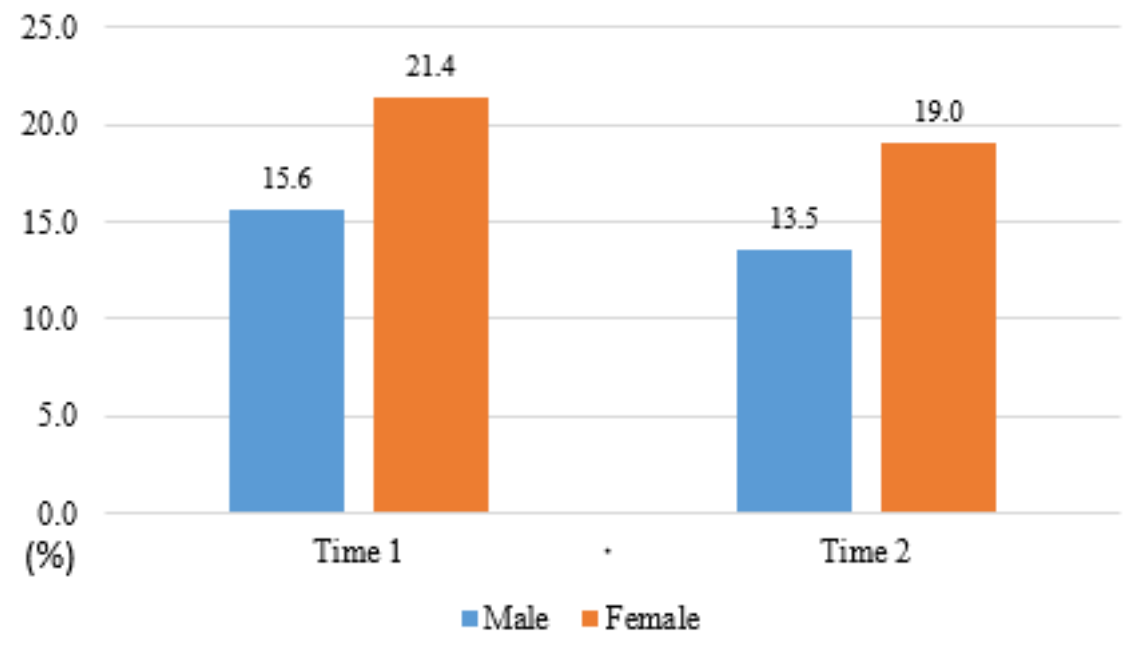

Figure 9. Poor self-perceived mental health, by gender.

In Figure 10, the rates of reporting poor mental health decreased with age at Time 1 . Those aged 15 to $24(33.3 \%)$ were most likely to have poor SPMH, whereas those aged 75 and over were least likely (2.2\%). In contrast, at Time 2, individuals aged 25 to 34 surpassed all other age groups with $27.1 \%$ reporting poor mental health. Four out of seven age groups (except 25 to 34,45 to 54 , and $75+$ ) had a lower rate of poor SMPH from Time 1 to Time 2. The difference over time was particularly evident for those aged 15 to 24 . Poor mental health was reported by $33.3 \%$ at Time 1 compared to $23.5 \%$ at Time 2 . Overall, those aged 55 and over were less likely to report poor mental health than other younger age groups at both time points.

The International Journal of Information, Diversity, \& Inclusion, 5(3), 2021

ISSN 2574-3430, jps.library.utoronto.ca/index.php/ijidi/index

DOI: $10.33137 /$ ijidi.v5i3.36193 


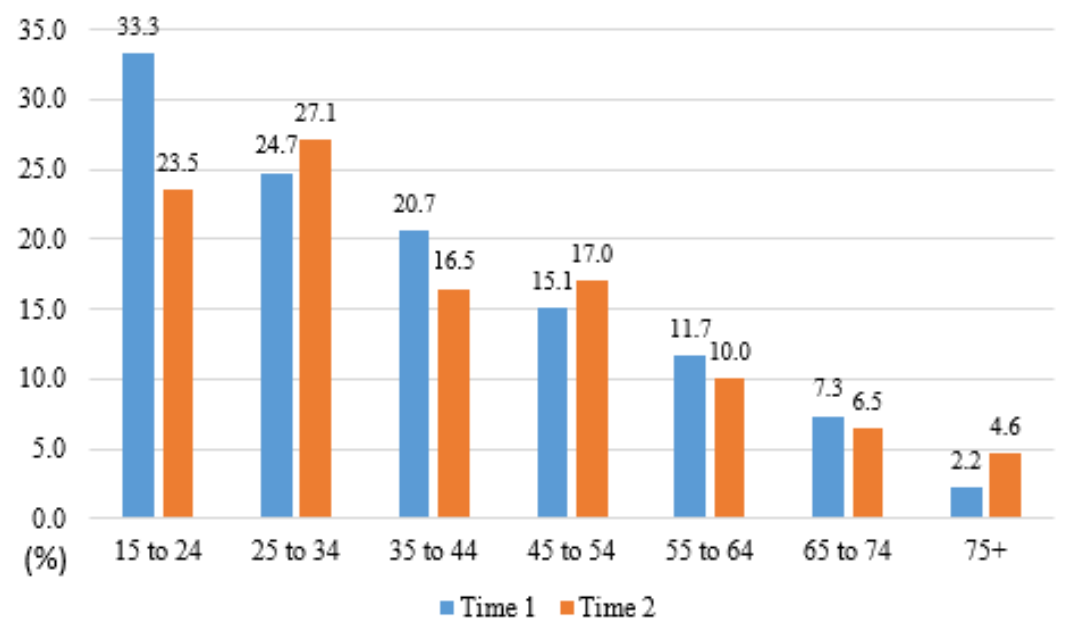

Figure 10. Poor self-perceived mental health, by age group

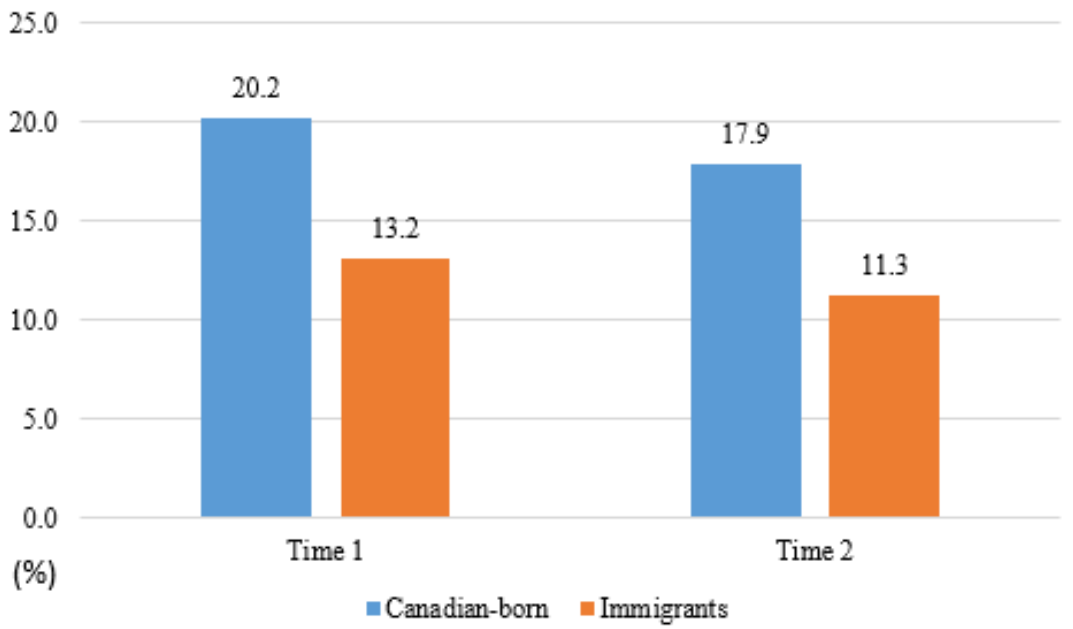

Figure 11. Poor self-perceived mental health, by immigration status

As shown in Figure 11, immigrants were less likely to report poor SPMH than the Canadian-born population regardless of the time point. At Time 1, 13.2\% of the immigrants reported poor SPMH as compared to $20.2 \%$ of the Canadian-born individuals. At Time 2, the rates dropped for both subgroups, although the difference was slightly smaller than Time 1.

\section{Associations between Sources of Information and Poor SPMH}

Logistic regression model (1) was run separately for Time 1 and Time 2 to assess the relationships between information sources and poor SPMH outcome, after controlling for all covariates. The results are presented in the first two columns of Table 2. At Time 1, for Canadians consulting any source of information, the odds of reporting poor SPMH were not significantly different after controlling for covariates. In comparison, at Time 2, using six information sources was found to

The International Journal of Information, Diversity, \& Inclusion, 5(3), 2021

ISSN 2574-3430, jps.library.utoronto.ca/index.php/ijidi/index

DOI: $10.33137 /$ ijidi.v5i3.36193 
be significantly associated with lower odds of reporting poor SPMH compared to using social media. Specifically, the odds of reporting poor SPMH from consulting news outlets $(0.55)$ and provincial health agency $(0.51)$ were approximately halved compared to using social media. Those consulting federal health agencies, places of employment, and provincial daily announcements had even lower odds of reporting poor SPMH, with odds ratios ranging from 0.30 to 0.43 . For the individuals getting information mainly from other sources (schools, colleges, universities), the odds of reporting poor SPMH were $86 \%$ lower than those using social media.

In addition to information sources, the estimation of the regression model in Table 2 yields a few other statistically significant variables. Results for Time 2 are highlighted only if they are different from the ones from Time 1. At Time 1, the odds of reporting poor SPMH significantly decreased with an increase in age. Compared with the Canadian-born population, the odds that immigrants reported poor SPMH were almost halved. Having very good or excellent self-rated health, and doing more activities to improve health were significantly associated with lower odds of poor mental health outcome. On the other hand, having more concerns about the impacts of COVID-19, unemployment status, and having a high school education significantly increased the odds of reporting poor SPMH. Compared with those living in single detached houses, the odds of reporting poor SPMH for individuals living in high-rise apartments more than doubled. At Time 2, the younger age groups 25 to 34,35 to 44 , and 45 to 54 lost significance, whereas the older age groups 55 to 64,65 to 74, and 75+ remained significant, with older people having lower odds of reporting poor SPMH. High school education and unemployment status lost significance. Living in low-rise apartments significantly increased odds of poor SPMH, and having good self-rated health significantly decreased such odds. The logistic regression analysis did not find a significant difference between females and males in the adjusted odds of poor SPMH.

This research also assessed the association between checking the accuracy of online information and poor SPMH. The variable "checking accuracy" was added to the model, which included five categories: always, often, sometimes, rarely, and never. As data for this variable were only available in CPSS4, a logistic regression analysis was performed on a sample of 3,268 records from Time 2 only. The results are presented in the last column of Table 2. The findings indicated that those always checking the accuracy of online information had 2.72 times lower odds than those checking sometimes, and had 3.46 times lower odds than those who never checked, after other factors were accounted for.

Table 2. Logistic Regressions with Odds Ratios Displaying Impacts on Poor SPMH

\begin{tabular}{llll}
\hline & Time 1 & Time 2 & Time 2 \\
\hline Variables & $(1)$ & $(1)$ & $(2)$ \\
\hline Information Source & Odds ratio & Odds ratio & Odds ratio \\
Social media (ref) & 1.00 & 1.00 & \\
News outlets & $1.03(0.17)$ & $0.55(0.09)^{*}$ & $0.52(0.09)^{*}$ \\
Federal health agency & $1.63(0.39)$ & $0.30(0.14)^{*}$ & $0.27(0.14)^{*}$ \\
Provincial health agency & $1.37(0.32)$ & $0.51(0.12)^{*}$ & $0.51(0.13)^{*}$ \\
Municipal health agency & $1.21(0.97)$ & $0.87(0.38)$ & $0.83(0.37)$ \\
Federal daily announcement & $0.89(0.22)$ & $0.98(0.29)$ & $0.96(0.32)$ \\
Provincial daily announcement & $0.79(0.18)$ & $0.43(0.11)^{*}$ & $0.39(0.11)^{*}$
\end{tabular}

The International Journal of Information, Diversity, \& Inclusion, 5(3), 2021

ISSN 2574-3430, jps.library.utoronto.ca/index.php/ijidi/index

DOI: $10.33137 /$ ijidi.v5i3.36193 


\begin{tabular}{|c|c|c|c|}
\hline Family/friends/colleagues & $0.74(0.29)$ & $1.20(0.32)$ & $0.94(0.27)$ \\
\hline Health professionals & $2.10(0.80)$ & $0.58(0.24)$ & $0.77(0.34)$ \\
\hline Place of employment & $1.64(0.49)$ & $0.36(0.14)^{*}$ & $0.30(0.13)^{*}$ \\
\hline Other & $1.06(0.34)$ & $0.14(0.10)^{*}$ & $0.18(0.13)$ \\
\hline Did not look for information & $3.07(1.74)$ & $1.26(0.44)$ & \\
\hline \multicolumn{4}{|l|}{ Checking Accuracy } \\
\hline Always (ref) & & & 1.00 \\
\hline Often & & & $1.59(0.29)$ \\
\hline Sometimes & & & $2.72(0.53)^{*}$ \\
\hline Rarely & & & $1.50(0.36)$ \\
\hline Never & & & $3.46(0.97)^{*}$ \\
\hline \multicolumn{4}{|l|}{ Gender } \\
\hline Male (ref) & 1.00 & 1.00 & 1.00 \\
\hline Female & $1.24(0.12)$ & $1.31(0.15)$ & $1.23(0.15)$ \\
\hline \multicolumn{4}{|l|}{ Age Group } \\
\hline 15 to 24 (ref) & 1.00 & 1.00 & 1.00 \\
\hline 25 to 34 & $0.45(0.09)^{*}$ & $1.27(0.30)$ & $1.24(0.32)$ \\
\hline 35 to 44 & $0.38(0.08)^{*}$ & $0.67(0.17)$ & $0.73(0.20)$ \\
\hline 45 to 54 & $0.22(0.05)^{*}$ & $0.60(0.15)$ & $0.67(0.17)$ \\
\hline 55 to 64 & $0.12(0.03)^{*}$ & $0.27(0.07)^{*}$ & $0.30(0.09)^{*}$ \\
\hline 65 to 74 & $0.06(0.02)^{*}$ & $0.16(0.05)^{*}$ & $0.12(0.04)^{*}$ \\
\hline $75+$ & $0.01(0.01)^{*}$ & $0.08(0.04)^{*}$ & $0.07(0.04)^{*}$ \\
\hline \multicolumn{4}{|l|}{ Immigration Status } \\
\hline Canadian-born (ref) & 1.00 & 1.00 & 1.00 \\
\hline Immigrant & $0.49(0.06)^{*}$ & $0.43(0.07)^{*}$ & $0.49(0.08)^{*}$ \\
\hline \multicolumn{4}{|l|}{ Marital Status } \\
\hline Single/widowed/divorced (ref) & 1.00 & 1.00 & 1.00 \\
\hline Married/common-law & $0.76(0.12)$ & $0.80(0.14)$ & $0.90(0.17)$ \\
\hline \multicolumn{4}{|l|}{ Education } \\
\hline Less than high school (ref) & 1.00 & 1.00 & 1.00 \\
\hline High School & $1.53(0.25)^{*}$ & $0.84(0.16)$ & $0.78(0.17)$ \\
\hline College & $1.50(0.27)$ & $0.96(0.20)$ & $0.97(0.22)$ \\
\hline Bachelors & $1.21(0.24)$ & $0.64(0.15)$ & $0.62(0.16)$ \\
\hline Advanced & $1.14(0.29)$ & $0.85(0.23)$ & $0.78(0.23)$ \\
\hline \multicolumn{4}{|l|}{ Employment Status } \\
\hline Employed and at work (ref) & 1.00 & 1.00 & 1.00 \\
\hline Absent not due to COVID-19 & $1.09(0.26)$ & $0.82(0.20)$ & $0.82(0.20)$ \\
\hline Absent due to COVID-19 & $1.05(0.18)$ & $1.11(0.33)$ & $1.15(0.36)$ \\
\hline Not employed & $1.47(0.18)^{*}$ & $1.10(0.15)$ & $1.06(0.15)$ \\
\hline \multicolumn{4}{|l|}{ Dwelling Type } \\
\hline Single detached house (ref) & 1.00 & 1.00 & 1.00 \\
\hline Low-rise apartment & $1.01(0.17)$ & $1.66(0.29)^{*}$ & $1.64(0.31)^{*}$ \\
\hline High-rise apartment & $2.05(0.37)^{*}$ & $2.04(0.40)^{*}$ & $1.54(0.34)$ \\
\hline Other & $1.23(0.16)$ & $0.77(0.12)$ & $0.72(0.12)$ \\
\hline
\end{tabular}

The International Journal of Information, Diversity, \& Inclusion, 5(3), 2021

ISSN 2574-3430, jps.library.utoronto.ca/index.php/ijidi/index

DOI: $10.33137 /$ ijidi.v5i3.36193 


\begin{tabular}{llll}
$\begin{array}{l}\text { Household Size } \\
1 \text { (ref) }\end{array}$ & 1.00 & 1.00 & 1.00 \\
2 & $0.89(0.17)$ & $0.91(0.19)$ & $0.75(0.17)$ \\
3 & $0.73(0.15)$ & $0.71(0.17)$ & $0.57(0.15)$ \\
4 & $0.73(0.17)$ & $0.87(0.24)$ & $0.66(0.20)$ \\
$5+$ & $1.08(0.30)$ & $1.48(0.47)$ & $1.27(0.44)$ \\
Self-Rated Health & & & \\
Poor (ref) & 1.00 & 1.00 & 1.00 \\
Fair & $1.77(0.72)$ & $0.82(0.34)$ & $1.10(0.54)$ \\
Good & $0.41(0.16)$ & $0.11(0.05)^{*}$ & $0.15(0.07)^{*}$ \\
Very Good & $0.13(0.05)^{*}$ & $0.04(0.02)^{*}$ & $0.06(0.03)^{*}$ \\
Excellent & $0.06(0.03)^{*}$ & $0.01(0.00)^{*}$ & $0.01(0.00)^{*}$ \\
Precautions & $1.06(0.02)$ & $1.06(0.03)$ & $1.12(0.03)^{*}$ \\
Activities & $0.79(0.04)^{*}$ & $0.83(0.04)^{*}$ & $0.83(0.04)^{*}$ \\
Concerns & $1.03(0.01)^{*}$ & $1.05(0.01)^{*}$ & $1.07(0.01)^{*}$ \\
Constant & $1.48(0.79)$ & $2.59(1.49)$ & $0.70(0.47)$ \\
Observations & 3862 & 3795 & 3268 \\
\hline
\end{tabular}

seEform in parentheses

${ }^{*} p<0.01$

\section{Discussions}

\section{Mental Health Change over Time}

The current study examined the impacts of COVID-19 on mental health among Canadians aged 15 and older during March and July 2020. Canadians at Time 1 reported $18.6 \%$ fair or poor selfperceived mental health while Time 2 reported $16.3 \%$, with both outcomes being substantially higher than 7.5\% revealed by Canadian Community Health Survey (2017-2018) (Statistics Canada, 2019). Deterioration of mental health resulting from this pandemic aligns with reports from Canada (Findley \& Arim, 2020) and other countries (Gao et al., 2020; Lee et al., 2021). These findings are consistent with the previous studies that suggest a public health crisis such as H1N1 (Lau et al., 2010), Ebola (Ji et al., 2017; Cénat et al., 2020), and SARS (Mak et al., 2009) can lead to mental health problems. A decline in the rate of poor SPMH at Time 2 coincided with the decrease in the 7-day average of COVID-19 new case number in Canada, and with provinces announcing plans for reopening (Office of the Premier, 2020). It could also be due to the mental health interventions undertaken by the government and organizations.

On April 15, 2020 the federal government launched Wellness Together Canada to support mental wellness (Health Canada, 2020). A group of existing mental health organizations ran this platform to help Canadians find credible information and obtain professional support. Moreover, the Centre for Addiction and Mental Health (2020) provided mental health information sheets and coping tips for the public and health care providers. Mental health information was also available through the Mental Health Commission of Canada and Kids Help Phone, among others. These interventions may help address mental health issues, thus lowering the proportion of individuals reporting poor SPMH. Despite a slight improvement, it is still of utmost importance to monitor Canadians' mental health as the pandemic is far from over yet.

The International Journal of Information, Diversity, \& Inclusion, 5(3), 2021

ISSN 2574-3430, jps.library.utoronto.ca/index.php/ijidi/index

DOI: $10.33137 /$ ijidi.v5i3.36193 


\section{Influencing Factors of Poor SPMH}

\section{Information sources}

Social media is one of the main channels to get updates on COVID-19. This study found that about $10 \%$ of Canadians used social media as their main information source. Using social media correlated with higher adjusted odds of poor SPMH than other six information sources. These effects became significant when Canadians were five months into the pandemic. Previous studies from other countries have revealed that frequent social media exposure is a predictor of mental health problems (Feder et al. 2020; Gao et al., 2020; Li et al., 2021; Ni et al., 2020). To my knowledge, the present study is the first longitudinal study of determinants of mental health that compares the effects of social media and other information sources during COVID-19. The findings from this research has added Canadian evidence that it is critical to select credible information sources to support mental health and wellbeing.

Additionally, frequently checking the accuracy of information on the internet is essential to lower the risk of having poor mental health. Government agencies, mental health associations or organizations, and libraries can play a role in strengthening public education about COVID-19 information literacy. As defined by the American Library Association (1989), "Information literacy is a set of abilities requiring individuals to recognize when information is needed and have the ability to locate, evaluate, and use effectively the needed information." The focus of public education would be to develop public awareness of how to search and evaluate pandemicrelated information for credibility and authority. Public education may take many forms such as posters, workshops, radio/TV programs, or web pages providing useful resources. Particularly, this research found that females, immigrants, and those aged 25-34 were the demographic subgroups more likely to use social media at both time points. Hence, it is important to increase their awareness of the type of information available on social media. Misinformation and negative feelings expressed on social media are contagious. Staying away from such information will be beneficial to their mental health.

\section{Demographic Factors}

Older people faced increased risk of severe illness from COVID-19 and had a higher mortality rate than younger people (Yanez et al., 2020; Mallapaty, 2020). Nevertheless, this research found that persons aged 55 years or older had a strikingly lower likelihood of poor SPMH than those aged 15 to 24 at both time points. This result is consistent with other research showing the association between younger age and greater mental health problems during the pandemic (Huang \& Zhao, 2020; Zhou et al., 2020; Thomas et al., 2020; Smith et al., 2020). There may be several reasons explaining this association. On one hand, emotional experience improves with age. Older people have more positive overall emotional well-being and greater emotional stability than younger people (Carstensen et al., 2011). The coping behaviours also play a significant role in developing resilience among older people, for example, religious coping in disasters such as a flood (Cherry et al., 2021), and positive coping during the COVID-19 pandemic (Minahan et al., 2021). Moreover, older people have psychosocial strengths derived from life reflection, adaptive use of personal memory, and generativity (Lind et al., 2021). On the other hand, some changes due to the pandemic may disproportionately affect younger people and have a stronger negative effect on their mental health (e.g., cancellation of in-person classes, reduced social interactions due to school closures, diminishing summer/part-time job opportunities). It is important to note that only $13.07 \%$ of the sample are aged 65 to 74 and $3.85 \%$ are aged 75 and

The International Journal of Information, Diversity, \& Inclusion, 5(3), 2021

ISSN 2574-3430, jps.library.utoronto.ca/index.php/ijidi/index

DOI: $10.33137 /$ ijidi.v5i3.36193 
over. The CPSS was not conducted in long-term care residences where 70 years and older were found to have higher age-specific case fatality rates (Public Health Ontario, 2021), or in remote areas with low population density. These factors need to be considered when interpreting the results from this study.

Immigration status demonstrated a consistent effect on mental health at both time points. Poor SPMH was significantly lower among immigrants than the Canadian-born population. Despite different measures used to examine mental health, this finding is consistent with previous Canadian studies (Ali, 2002; Akhtar-Danesh \& Landeen, 2007; Lou \& Beaujot, 2005; Menezes et al., 2011; Schaffer et al., 2009). This could be partially explained by migration resilience, which is regarded as "successful outcomes to the serious threats towards adaptation and development" (Akbar \& Preston, 2019, p.11). Immigrants are confronted with a wide range of challenges associated with the settlement and integration process (Akbar \& Preston, 2019). The stressors to their mental health include unemployment or underemployment, lack of community-belonging and social support, discrimination/racism, and more (Salami et al., 2017). Immigrants may have developed resilience as they try every means to settle and develop in Canada. Hence, they have considerable strength to cope better despite the adversities of the pandemic. Therefore, more mental health intervention needs to be given to the Canadian-born population. Despite a lower rate of poor SPMH among immigrants, it is noteworthy to point out that the current pandemic may affect immigrants in a unique way. Addressing the mental health issue among immigrants is also important. Regardless of COVID-19, immigrants have experienced difficulties accessing health care services which causes emotional problems (Robert \& Gilkinson, 2012). During the pandemic, due to lack of translated information about COVID-19, immigrants with limited English proficiency may find it harder to access credible information themselves, or navigate the healthcare system to get help from professionals.

This research also found that having more COVID-related concerns was a significant factor of poorer mental health, which is consistent with Thomas et al. (2020). The improvement of selfrated health condition significantly accompanied the decreased odds of poor mental health, as supported by Gao et al. (2020). Engagements in healthy activities (like meditation, exercising indoors, exercising outdoors, communication with family and friends, and changing food choices) would help reduce the risk of poor mental health. These factors should be taken into consideration for effective mental health intervention during the current pandemic.

\section{Limitations}

Some limitations should be noted in this study. First, in the current digital world, it is common that news organizations, public health agencies, and governments impart pandemic-related information to the public through social media for a broader readership. They normally post such information on their websites and provide links to that information on their social media sites. In CPSS1 and CPSS4, the question about one's main source of COVID-19 information did not specify that a respondent should select news outlets if they obtained the same information linked through social media, for example, a CBC News' Facebook post or Twitter feed. Thus, there was no way of knowing which category a respondent selected in such a situation. This type of measurement error may affect estimates in this research.

Second, this research uses self-perceived mental health measures and some subjective control variables (self-rated health, respondent's perception of concerns). Reporting errors may occur due to non-objectivity. Cultural differences are found to be correlated with respondents'

The International Journal of Information, Diversity, \& Inclusion, 5(3), 2021

ISSN 2574-3430, jps.library.utoronto.ca/index.php/ijidi/index

DOI: $10.33137 /$ ijidi.v5i3.36193 
willingness to report their own mental health state. Some immigrants may feel ashamed to have mental health issues and prefer not to disclose their status to others to avoid stigma (Salami et al., 2017). Thus, the prevalence of poor mental health among immigrants could have been underreported in this research.

Third, due to limitations of the CPSS1 and CPSS4 data, many influencing factors of mental health are unexamined, such as income, pre-existing chronic diseases, self or loved ones testing positive for COVID-19, and having a history of mental health problems. The logistic regression analysis does not examine the time spent or frequency of using social media as in Ni et al. (2020), Gao et al. (2020) and Feder et al. (2020), nor does it explore an array of social media platforms as in Ahmad and Murad (2020). Moreover, only two points in time are available for longitudinal analysis. The results are representative of the study period being relatively early during the COVID-19 period. More research is essential as we are still processing the pandemic one year later.

\section{Conclusion}

Using two CPSS datasets, this study provides a longitudinal analysis of Canadians' mental health during March and July 2020, focusing on the information sources Canadians used and their associations with poor self-perceived mental health. The logistic regression results revealed that at Time 2 (July 2020), using social media was significantly associated with higher adjusted odds of poor mental health than using six other information sources, including news outlets, federal health agencies, provincial health agencies, provincial daily announcements, places of employment, and other sources (schools, colleges, universities). Participants who always checked the accuracy of online information had significantly lower odds of poor self-perceived mental health than those who sometimes or never checked. These findings suggested that public education would be needed to improve Canadians' abilities to select and evaluate COVID-19 information for credibility and authority. Despite a decline in the prevalence of poor selfperceived mental health over time, continued attention should be paid to monitor and improve Canadians' mental health as the pandemic is far from over yet. Further research efforts can seek to examine the factors that may influence the individual choices of these information sources, the effects of specific social media networks on one's mental health, and the evolving patterns of Canadians' information seeking behaviours over a longer period.

\section{Acknowledgements}

The author would like to thank Lenka Mach, Senior Methodologist at the Data Analysis Resource Centre of Statistics Canada, who provided valuable guidance in the statistical analysis part of this paper. However, the author takes full responsibility for all analysis and interpretation of the data. The author is also grateful to the editors and peer reviewers for their thoughtful comments that helped revise and improve the manuscript.

The International Journal of Information, Diversity, \& Inclusion, 5(3), 2021

ISSN 2574-3430, jps.library.utoronto.ca/index.php/ijidi/index

DOI: $10.33137 /$ ijidi.v5i3.36193 


\section{Endnote}

${ }^{1}$ When discussing gender-based differences, this article discusses males and females only. This is because the data sets consulted in the research only had data for these two genders. While gender is non-binary, some data does not yet reflect this.

\section{References}

Ahmad, A. R., \& Murad, H. R. (2020). The impact of social media on panic during the COVID-19 pandemic in Iraqi Kurdistan: Online questionnaire study. Journal of Medical Internet Research, 22(5), Article e19556. https://doi.org/10.2196/19556

Akbar, M. \& Preston, V. (2019). Migration and resilience. Building Migrant Resilience in Cities/ Immigration et résilience en milieu urbain. https://bmrcirmu.info.yorku.ca/files/2020/06/Immigrants-and-Resilience-WorkingPaper_Final_new7.pdf?x15611

Akhtar-Danesh, N., \& Landeen, J. (2007). Relation between depression and sociodemographic factors. International Journal of Mental Health Systems, 1(4).

https: //doi.org/10.1186/1752-4458-1-4

AlGhamdi, K. M., \& Moussa, N. A. (2012). Internet use by the public to search for healthrelated information. International Journal of Medical Informatics, 81(6), 363-373. https://doi.org/10.1016/j.ijmedinf.2011.12.004

Ali, J. (2002). Mental health of Canada's immigrants. Health Reports, 13 (Suppl.), 1-11. https://www150.statcan.gc.ca/n1/en/pub/82-003-s/2002001/pdf/82-003-s2002006eng.pdf?st=OmdCZG3H

American Library Association. (1989). Presidential Committee on information literacy: Final report. https: //www.ala.org/acrl/publications/whitepapers/presidential

Amerio, A., Brambilla, A., Morganti, A., Aguglia, A., Bianchi, D., Santi, F., Costantini, L., Odone, A., Costanza, A., Signorelli, C., Serafini, G., Amore, M., \& Capolongo, S. (2020). COVID-19 lockdown: Housing built environment's effects on mental health. International Journal of Environmental Research and Public Health, 17(16), Article 5973. https://doi.org/10.3390/ijerph17165973

Anker, A. E., Reinhart, A. M., \& Feeley, T. H. (2011). Health information seeking: A review of measures and methods. Patient Education and Counseling, 82(3), 346-354. https://doi.org/10.1016/j.pec.2010.12.008

Asmundson, G. J. G., \& Taylor, S. (2020a). Coronaphobia: Fear and the 2019-nCoV outbreak. Journal of Anxiety Disorders, 70, Article 102196. https://doi.org/10.1016/j.janxdis.2020.102196 
Asmundson, G. J. G., \& Taylor, S. (2020b). How health anxiety influences responses to viral outbreaks like COVID-19: What all decision-makers, health authorities, and health care professionals need to know. Journal of Anxiety Disorders, 71, Article 102211. https://doi.org/10.1016/j.janxdis.2020.102211

Bassi, M., Negri, L., Delle Fave, A., \& Accardi, R. (2021). The relationship between posttraumatic stress and positive mental health symptoms among health workers during COVID-19 pandemic in Lombardy, Italy. Journal of Affective Disorders, 280(Part B), 1 6. https://doi.org/10.1016/j.jad.2020.11.065

Beaudoin, C. E., \& Hong, T. (2011). Health information seeking, diet and physical activity: An empirical assessment by medium and critical demographics. International Journal of Medical Informatics, 80(8), 586-595. https://doi.org/10.1016/j.ijmedinf.2011.04.003

Berryman, C., Ferguson, C. J., \& Negy, C. (2018). Social media use and mental health among young adults. Psychiatric Quarterly, 89(2), 307-314. https://doi.org/10.1007/s11126017-9535-6

Canadian Mental Health Association (CMHA). (2021, May 3). Summary of findings mental health impacts of COVID-19: Round 3. https://cmha.ca/wp-content/uploads/2021/05/CMHAUBC-Round-3-Summary-of-Findings-FINAL-EN.pdf

Canadian Public Health Association. (2021, February 16). Review of Canada's initial response to the COVID-19 pandemic. https://www.cpha.ca/review-canadas-initial-response-covid19-pandemic

Carstensen, L. L., Turan, B., Scheibe, S., Ram, N., Ersner-Hershfield, H., Samanez-Larkin, G. R., Brooks, K. P., \& Nesselroade, J. R. (2011). Emotional experience improves with age: Evidence based on over 10 years of experience sampling. Psychology and Aging, 26(1), 21-33. https://doi.org/10.1037/a0021285

Cénat, J. M., Felix, N., Blais-Rochette, C., Rousseau, C., Bukaka, J., Derivois, D., Noorishad, P. G., \& Birangui, J. P. (2020). Prevalence of mental health problems in populations affected by the Ebola virus disease: A systematic review and meta-analysis. Psychiatry Research, 289, Article 113033. https://doi.org/10.1016/j.psychres.2020.113033

Centre for Addiction and Mental Health (CAMH). (2020, July). Mental health in Canada: Covid19 and beyond CAMH policy advice. https: / / www.camh.ca/-/media/files/pdfs---publicpolicy-submissions/covid-and-mh-policy-paper-pdf.pdf

Charnock, S., Heisz, A., Kaddatz, J., Spinks, N., \& Mann, R. (2021). Canadians' well-being in year one of the COVID-19 pandemic. https://www150.statcan.gc.ca/n1/en/pub/75f0002m/75f0002m2021003eng.pdf?st=RvEHLeLG

Cherry, K. E., De Vito, A. N., Calamia, M. R., Elliott, E. M., Yu, S., Sampson, L., Galea, S., Mansoor, M., McKneely, K. J., \& Nguyen, Q. P. (2021). Disaster stressors and psychological well-being in older adults after a flood. Psychology and Aging. https://doi-org.libproxy.wlu.ca/10.1037/pag0000602

The International Journal of Information, Diversity, \& Inclusion, 5(3), 2021

ISSN 2574-3430, jps.library.utoronto.ca/index.php/ijidi/index

DOI: $10.33137 /$ ijidi.v5i3.36193 
Chi, X., Becker, B., Yu, Q., Willeit, P., Jiao, C., Huang, L., Hossain, M. M., Grabovac, I., Yeung, A., Lin, J., Veronese, N., Wang, J., Zhou, X., Doig, S. R., Liu, X., Carvalho, A. F., Yang, L., Xiao, T., Zou, L., ... Solmi, M. (2020). Prevalence and psychosocial correlates of mental health outcomes among Chinese college students during the coronavirus disease (COVID-19) pandemic. Frontiers in Psychiatry, 11, Article 803. https://doi.org/10.3389/fpsyt.2020.00803

Coyne, S. M., Rogers, A. A., Zurcher, J. D., Stockdale, L., \& Booth, M. (2020). Does time spent using social media impact mental health?: An eight year longitudinal study. Computers in Human Behavior, 104, Article 106160. https://doi.org/10.1016/j.chb.2019.106160

CTV News. (2021, January 25). Grim anniversary: A timeline of one year of COVID-19. https://www.ctvnews.ca/health/coronavirus/grim-anniversary-a-timeline-of-one-yearof-covid-19-1.5280617

Eaton, W. W., Neufeld, K., Chen, L. S., \& Cai, G. (2000). A comparison of self-report and clinical diagnostic interviews for depression: Diagnostic interview schedule and schedules for clinical assessment in neuropsychiatry in the Baltimore epidemiologic catchment area follow-up. Archives of General Psychiatry, 57(3), 217-222. https://doi.org/10.1001/archpsyc.57.3.217

Evra, R., \& Mongrain, E. (2020). Mental health status of Canadian immigrants during the COVID-19 pandemic. https://www150.statcan.gc.ca/n1/en/pub/45-28$0001 / 2020001 /$ article/00050-eng.pdf?st=f-VihzHx

Feder, K. A., Riehm, K. E., \& Mojtabai, R. (2020). Is there an association between social media use and mental health? The timing of confounding measurement matters - reply. JAMA Psychiatry, 77(4), 438. https://doi.org/10.1001/jamapsychiatry.2019.4503

Findlay, L., \& Arim, R. (2020). Canadians report lower self-perceived mental health during the COVID-19 pandemic. https://www150.statcan.gc.ca/n1/pub/45-280001/2020001/article/00003-eng.htm

Gao, J., Zheng, P., Jia, Y., Chen, H., Mao, Y., Chen, S., Wang, Y., Fu, H., \& Dai, J. (2020). Mental health problems and social media exposure during COVID-19 outbreak. PLoS ONE, 15(4), Article e0231924. https://doi.org/10.1371/journal.pone.0231924

Government of Canada. (2021). Coronavirus disease 2019 (COVID-19): Epidemiology update. Retrieved June 18, 2021 from https: //health-infobase.canada.ca/covid19/epidemiological-summary-covid-19-cases.html

Grekou, D., \& Lu, Y. (2021). Gender differences in employment one year into the COVID-19 pandemic: An analysis by industrial sector and firm size. Social and Economic Reports, 1(5), 1-15. https://www150.statcan.gc.ca/n1/pub/36-28-0001/2021005/article/00005eng.htm

Health Canada. (2020, April 15). Government of Canada connects Canadians with mental wellness supports during COVID-19. https: / /www.canada.ca/en/healthcanada/news/2020/04/government-of-canada-connects-canadians-with-mentalwellness-supports-during-covid-190.html

The International Journal of Information, Diversity, \& Inclusion, 5(3), 2021

ISSN 2574-3430, jps.library.utoronto.ca/index.php/ijidi/index

DOI: 10.33137/ijidi.v5i3.36193 
Holmes, E. A., O'Connor, R. C., Perry, V. H., Tracey, I., Wessely, S., Arseneault, L., Ballard, C., Christensen, H., Silver, R. C., Everall, I., Ford, T., John, A., Kabir, T., King, K., Madan, I., Michie, S., Przybylski, A. K., Shafran, R., Sweeney, A., ... Bullmore, E. (2020). Multidisciplinary research priorities for the COVID-19 pandemic: A call for action for mental health science. The Lancet Psychiatry, 7(6), 547-560.

https: // doi.org/10.1016/S2215-0366(20)30168-1

Huang, Y., \& Zhao, N. (2020). Generalized anxiety disorder, depressive symptoms and sleep quality during COVID-19 outbreak in China: A web-based cross-sectional survey. Psychiatry Research, 288, Article 112954. https://doi.org/10.1016/j.psychres.2020.112954

Ji, D., Ji, Y. J., Duan, X. Z., Li, W. G., Sun, Z. Q., Song, X. A., Meng, Y. H., Tang, H. M., Chu, F., Niu, X. X., Chen, G. F., Li, J., \& Duan, H. J. (2017). Prevalence of psychological symptoms among Ebola survivors and healthcare workers during the 2014-2015 Ebola outbreak in Sierra Leone: A cross-sectional study. Oncotarget, 8(8), 12784-12791. https://doi.org/10.18632/oncotarget.14498

Johnson, J. D., Andrews, J. E., \& Allard, S. (2001). A model for understanding and affecting cancer genetics information seeking. Library \& Information Science Research, 23(4), 335-349. https: //doi.org/10.1016/S0740-8188(01)00094-9

Kelland, K. (2020, May 13). U.N. warns of global mental health crisis due to COVID-19 pandemic. https://www.reuters.com/article/us-health-coronavirus-mentalhealthidUSKBN22Q0AO

LaRochelle-Côté, S., \& Uppal, S. (2020). The social and economic concerns of immigrants during the COVID-19 pandemic. https://www150.statcan.gc.ca/n1/en/pub/45-280001/2020001/article/00012-eng.pdf?st=1e-guCTA

Lau, J. T., Griffiths, S., Choi, K. C., \& Tsui, H. Y. (2010). Avoidance behaviours and negative psychological responses in the general population in the initial stage of the H1N1 pandemic in Hong Kong. BMC Infectious Diseases, 10, Article 139. https: / / doi.org/10.1186/1471-2334-10-139

Lee, H.-S., Dean, D., Baxter, T., Griffith, T., \& Park, S. (2021). Deterioration of mental health despite successful control of the COVID-19 pandemic in South Korea. Psychiatry Research, 295, Article 113570. https://doi.org/10.1016/j.psychres.2020.113570

Li, Y., Zhao, J., Ma, Z., McReynolds, L. S., Lin, D., Chen, Z., Wang, T., Wang, D., Zhang, Y., Zhang, J., Fan, F., \& Liu, X. (2021). Mental health among college students during the COVID-19 Pandemic in China: A 2-wave longitudinal survey. Journal of Affective Disorders, 281(Complete), 597-604. https://doi.org/10.1016/j.jad.2020.11.109

Lind, M., Bluck, S., \& McAdams, D. P. (2021). More vulnerable? The life story approach highlights older people's potential for strength during the pandemic. The Journals of Gerontology: Series B, 76(2), e45-e48. https://doi.org/10.1093/geronb/gbaa105 
Lou, Y. M. \& Beaujot, R. P. (2005). What happens to the "healthy immigrant effect": The mental health of immigrants to Canada. PSC Discussion Papers Series, 19(15), Article 1. https://ir.lib.uwo.ca/pscpapers/vol19/iss15/1

Lu, L., Liu, J., \& Yuan, Y. C. (2020). Health information seeking behaviors and source preferences between Chinese and U.S. Populations. Journal of Health Communication, 25(6), 490-500. https://doi.org/10.1080/10810730.2020.1806414

Lwin, M. O., Lu, J., Sheldenkar, A., Schulz, P. J., Shin, W., Gupta, R., \& Yang, Y. (2020). Global sentiments surrounding the COVID-19 pandemic on Twitter: Analysis of Twitter trends. JMIR Public Health and Surveillance, 6(2), Article e19447. https://doi.org/10.2196/19447

Mak, I. W. C., Chu, C. M., Pan, P. C., Yiu, M. G. C., \& Chan, V. L. (2009). Long-term psychiatric morbidities among SARS survivors. General Hospital Psychiatry, 31(4), 318-326. https://doi.org/10.1016/j.genhosppsych.2009.03.001

Mallapaty, S. (2020). The coronavirus is most deadly if you are older and male-New data reveal the risks. Nature, 585(7823), 16-17. https://doi.org/10.1038/d41586-020-02483-2

Mansfield, R., Patalay, P., \& Humphrey, N. (2020). A systematic literature review of existing conceptualisation and measurement of mental health literacy in adolescent research: Current challenges and inconsistencies. BMC Public Health, 20. https://doi.org/10.1186/s12889-020-08734-1

Mason, A., Salami, B., Salma, J., Yohani, S., Amin, M., Okeke-Ihejirika, P., \& Ladha, T. (2021). Health information seeking among immigrant families in Western Canada. Journal of Pediatric Nursing, 58(Complete), 9-14. https://doi.org/10.1016/j.pedn.2020.11.009

Menezes, N. M., Georgiades, K., \& Boyle, M. H. (2011). The influence of immigrant status and concentration on psychiatric disorder in Canada: A multi-level analysis. Psychological Medicine, 41(10), 2221-2231. https://doi.org/10.1017/S0033291711000213

Mental Health Commission of Canada (MHCC). (2021). Mental Health Indicators for Canada. https://www.mentalhealthcommission.ca/English/resources/mhcc-reports/mentalhealth-indicators-canada

Minahan, J., Falzarano, F., Yazdani, N., \& Siedlecki, K. L. (2021). The COVID-19 pandemic and psychosocial outcomes across age through the stress and coping framework. The Gerontologist, 61(2), 228-239. https://doi.org/10.1093/geront/gnaa205

Moyser, M. (2020). Gender differences in mental health during the COVID-19 pandemic Canada. Statistics Canada. https://www150.statcan.gc.ca/n1/pub/45-280001/2020001/article/00047-eng.htm

Naslund, J. A., Aschbrenner, K. A., McHugo, G. J., Unützer, J., Marsch, L. A., \& Bartels, S. J. (2019). Exploring opportunities to support mental health care using social media: A survey of social media users with mental illness. Early Intervention in Psychiatry, 13(3), 405-413. https: / / doi.org/10.1111/eip.12496

The International Journal of Information, Diversity, \& Inclusion, 5(3), 2021

ISSN 2574-3430, jps.library.utoronto.ca/index.php/ijidi/index

DOI: $10.33137 /$ ijidi.v5i3.36193 
$\mathrm{Ng}$, E. (2011). The healthy immigrant effect and mortality rates. Health Reports, 22(4), 1-6. https: / / www150.statcan.gc.ca/n1/en/pub/82-003-x/2011004/article/11588eng.pdf?st=5VBL-q-7

Ng, E., \& Zhang, H. (2020). The mental health of immigrants and refugees: Canadian evidence from a nationally linked database. Health Reports, 31(82), 1-12. https://www150.statcan.gc.ca/n1/en/pub/82-003-x/2020008/article/00001eng.pdf?st $=c Y \_d n U K-$

Ni, M. Y., Yang, L., Leung, C. M. C., Li, N., Yao, X. I., Wang, Y., Leung, G. M., Cowling, B. J., \& Liao, Q. (2020). Mental health, risk factors, and social media use during the COVID-19 epidemic and cordon sanitaire among the community and health professionals in Wuhan, China: Cross-sectional survey. JMIR Mental Health, 7(5), Article e19009. https://doi.org/10.2196/19009

Niederdeppe, J., Hornik, R. C., Kelly, B. J., Frosch, D. L., Romantan, A., Stevens, R. S., Barg, F. K., Weiner, J. L., \& Schwartz, J. S. (2007). Examining the dimensions of cancerrelated information seeking and scanning behavior. Health Communication, 22(2), 153167. https://doi.org/10.1080/10410230701454189

Office of the Premier. (2020, July 13). Nearly all businesses and public spaces to reopen in stage 3. https://news.ontario.ca/en/release/57575/nearly-all-businesses-and-publicspaces-to-reopen-in-stage-3

Oh, K. M., Zhou, Q. (Pearl), Kreps, G., \& Kim, W. (2014). The influences of immigration on health information seeking behaviors among Korean Americans and native Koreans. Health Education \& Behavior, 41(2), 173-185. https://doi.org/10.1177/1090198113496789

O’Reilly, M., Dogra, N., Hughes, J., Reilly, P., George, R., \& Whiteman, N. (2019). Potential of social media in promoting mental health in adolescents. Health Promotion International, 34(5), 981-991. https://doi.org/10.1093/heapro/day056

O'Reilly, M. (2020). Social media and adolescent mental health: The good, the bad and the ugly. Journal of Mental Health, 29(2), 200-206. https://doi.org/10.1080/09638237.2020.1714007

Public Health Ontario. (2021). COVID-19 in long-term care homes in Ontario: January 15, 2020 to February 28, 2021. https: //www.publichealthontario.ca//media/documents/ncov/epi/2020/06/covid-19-epi-ltch-residents.pdf?la=en

Qiu, J., Shen, B., Zhao, M., Wang, Z., Xie, B., \& Xu, Y. (2020). A nationwide survey of psychological distress among Chinese people in the COVID-19 epidemic: Implications and policy recommendations. General Psychiatry, 33(2), Article e100213. https://doi.org/10.1136/gpsych-2020-100213

Rajkumar, R. P. (2020). COVID-19 and mental health: A review of the existing literature. Asian Journal of Psychiatry, 52, Article 102066. https://doi.org/10.1016/j.ajp.2020.102066 
Robert, A., \& Gilkinson, T. (2012). Mental health and well-being of recent immigrants in Canada: Evidence from the Longitudinal Survey of Immigrants to Canada. https://www.canada.ca/content/dam/ircc/migration/ircc/english/pdf/researchstats/mental-health.pdf

Salami, B., Hegadoren, K., Bautista, L., Ben-Shlomo, Y., Diaz, E., Rammohan, A., \& Meherali, S. (2017). Mental health of immigrants and non-immigrants in Canada: evidence from the Canadian health measures survey and service provider interviews in Alberta. Policy Wise for Children and Families. https: / / policywise.com/wpcontent/uploads/resources/2017/04/2017-04APR-27-Scientific-Report-15SMSalamiHegadoren.pdf

Schaffer, A., Cairney, J., Cheung, A., Veldhuizen, S., Kurdyak, P., \& Levitt, A. (2009). Differences in prevalence and treatment of bipolar disorder among immigrants: Results from an epidemiologic survey. Canadian Journal of Psychiatry. 54(11), 734-742. https://doi.org/10.1177/070674370905401103

Smith, L., Jacob, L., Yakkundi, A., McDermott, D., Armstrong, N. C., Barnett, Y., LópezSánchez, G. F., Martin, S., Butler, L., \& Tully, M. A. (2020). Correlates of symptoms of anxiety and depression and mental wellbeing associated with COVID-19: A crosssectional study of UK-based respondents. Psychiatry Research, 291, Article 113138. https://doi.org/10.1016/j.psychres.2020.113138

Statistics Canada. (2019). Canadian Community Health Survey, 2017-2018: Annual Component [Public use microdata file]. https://odesi.ca/\#/details?uri=/odesi/cchs-82M0013-E2017-2018-Annual-component.xml

Statistics Canada. (2020a, April 8). Canadian Perspectives Survey Series (CPSS). https: / / www23. statcan.gc.ca/imdb/p2SV.pl?Function=getSurvey\&SDDS=5311

Statistics Canada. (2020b). Canadian Perspectives Survey Series (CPSS) Series 1: Impacts of COVID-19 [Public use microdata file]. https://odesi.ca/\#/details?uri=/odesi/cpss-5311E-2020-impact.xml

Statistics Canada. (2020c). Canadian Perspectives Survey Series (CPSS) Series 4: Information sources consulted during the pandemic [Public use microdata file]. https://odesi.ca/\#/details?uri=/odesi/cpss-5311-E-2020-sources.xml

Statistics Canada. (2020d). Analytical guide - Canadian Perspectives Survey Series 1: Impacts of COVID-19. https://www.statcan.gc.ca/eng/statisticalprograms/document/5311_D1_V1

Statistics Canada. (2020e). Analytical guide - Canadian Perspectives Survey Series 4: Information sources consulted during the pandemic. https://www.statcan.gc.ca/eng/statistical-programs/document/5311_D4_V1

Tasnim, S., Hossain, M. M., \& Mazumder, H. (2020). Impact of rumors and misinformation on COVID-19 in social media. Journal of Preventive Medicine and Public Health, 53(3), 171-174. https: //doi.org/10.3961/jpmph.20.094

The International Journal of Information, Diversity, \& Inclusion, 5(3), 2021

ISSN 2574-3430, jps.library.utoronto.ca/index.php/ijidi/index

DOI: $10.33137 /$ ijidi.v5i3.36193 
Thomas, J., Barbato, M., Verlinden, M., Gaspar, C., Moussa, M., Ghorayeb, J., Menon, A., Figueiras, M. J., Arora, T., \& Bentall, R. P. (2020). Psychosocial correlates of depression and anxiety in the United Arab Emirates during the COVID-19 pandemic. Frontiers in Psychiatry, 11, Article 564172. https://doi.org/10.3389/fpsyt.2020.564172

Vogel L., \& Eggertson L. (2020, June 12). COVID-19: A timeline of Canada's first-wave response. CMAJ News. https://cmajnews.com/2020/06/12/coronavirus-1095847/

Wang, M. P., Wang, X., Lam, T. H., Viswanath, K., \& Chan, S. S. (2013). Health information seeking partially mediated the association between socioeconomic status and self-rated health among Hong Kong Chinese. PLoS ONE, 8(12), Article e82720.

https://doi.org/10.1371/journal.pone.0082720

Wang, C., Pan, R., Wan, X., Tan, Y., Xu, L., Ho, C. S., \& Ho, R. C. (2020). Immediate psychological responses and associated factors during the initial stage of the 2019 coronavirus disease (COVID-19) epidemic among the general population in China. International Journal of Environmental Research and Public Health, 17(5), Article 1729. https://doi.org/10.3390/ijerph17051729

World Health Organization. (2018, March 30). Mental health: strengthening our response. https://www.who.int/news-room/fact-sheets/detail/mental-health-strengthening-ourresponse

Yanez, N. D., Weiss, N. S., Romand, J.-A., \& Treggiari, M. M. (2020). COVID-19 mortality risk for older men and women. BMC Public Health, 20(1), Article 1742. https://doi.org/10.1186/s12889-020-09826-8

Yoon, J., Huang, H., \& Kim, S. (2017). Trends in health information-seeking behaviour in the U.S. foreign-born population based on the Health Information National Trends Survey, 2005-2014. Information Research, 22(3). https: / /files.eric.ed.gov/fulltext/EJ1156403.pdf

Zhou, M., \& Guo, W. (2021). Subjective distress about COVID-19 and its social correlates: Empirical evidence from Hubei Province of China. Journal of Affective Disorders, 289(Complete), 46-54. https://doi.org/10.1016/j.jad.2021.04.026

Zhou, Y., MacGeorge, E. L., \& Myrick, J. G. (2020). Mental health and its predictors during the early months of the COVID-19 pandemic experience in the United States. International Journal of Environmental Research and Public Health, 17(17), Article 6315. https://doi.org/10.3390/ijerph17176315

Yanli Li (yli@wlu.ca) is the Business and Economics Librarian at Wilfrid Laurier University. She holds a Ph.D. in Economics from Renmin University of China, and Master of Library and Information Studies (MLIS) from the University of British Columbia. Her research interests lie within academic librarianship and information seeking behaviours.

The International Journal of Information, Diversity, \& Inclusion, 5(3), 2021

ISSN 2574-3430, jps.library.utoronto.ca/index.php/ijidi/index

DOI: $10.33137 /$ ijidi.v5i3.36193 